\title{
Estudo laboratorial de um solo tropical granular estabilizado quimicamente para fins de pavimentação
}

\author{
Laboratory study of a granular tropical \\ soil chemically stabilized for pavement \\ purposes
}

Mirella Talitha Rocha ${ }^{1}$, Lilian Ribeiro de Rezende ${ }^{1}$

\author{
${ }^{1}$ Universidade Federal de Goiás (UFG), Escola de Engenharia Civil e Ambiental, Programa de Pós-Graduação em Geo- \\ tecnia, Estruturas e Construção Civil, Goiânia, GO \\ e-mail: mirellarocha@yahoo.com.br; rezende.lilian@gmail.com
}

\begin{abstract}
RESUMO
A estabilização química é uma técnica adotada para melhorar solos regionais no emprego de sub-bases e bases de pavimentos. No entanto, as metodologias de dosagem utilizadas na prática são baseadas em ensaios simples e não conseguem prever e explicar o comportamento mecânico das misturas. Este estudo tem como objetivo analisar a estabilização química de um cascalho laterítico empregado na camada de base de uma rodovia. Para tanto, foi estudada a mistura utilizada na obra ( $78 \%$ cascalho, $20 \%$ de areia e $2 \%$ de cimento), bem como misturas do mesmo cascalho com 2,4 e $6 \%$ de cimento e de cal hidratada. Foram realizados ensaios laboratoriais para a caracterização do solo, compactação na energia Proctor intermediária, expansão, Índice de Suporte Califórnia, compressão simples e triaxial dinâmico das misturas moldadas na condição ótima de compactação para três tempos de cura ( 0,7 e 28 dias). Para interpretação dos resultados em termos de módulo de resiliência, foram realizadas análises numéricas com o programa KENLAYER. Para complementação das análises dos resultados de resistência foram realizados ensaios de difração de raios-X e microscopia eletrônica de varredura. Os resultados obtidos mostram que para o solo em questão, a estabilização química com cal pouco contribuiu com o aumento dos parâmetros de resistência. Já o uso do cimento apresentou maior potencial de utilização. As diferenças de comportamento observadas nos ensaios de compressão simples e triaxial dinâmico foram explicadas por mudanças que acontecem na microestrutura durante o processo de estabilização. Por fim, concluiu-se que o processo de estabilização de solos tropicais é complexo, sendo que ensaios mecânicos, como o triaxial dinâmico, e parâmetros não convencionais para análise de solos para pavimentação, como a relação água/cimento e porosidade, devem ser incorporados nas análises para a obtenção de resultados mais consistentes.
\end{abstract}

Palavras-chave: Ensaios laboratoriais. Estabilização de solos. Solo-cal. Solo-cimento. Pavimento asfáltico.

\section{ABSTRACT}

The chemical stabilization is a technique used to improve regional soils on the use of pavements subbases and bases. However, dosing methodologies still used in practice are based on simple tests, and cannot predict and explain the mixtures mechanical behavior. This study aims to analyze the chemical stabilization of a lateritic gravel used in the base layer of a highway. To this end, studied the mixture used in the site $(78 \%$ gravel, $20 \%$ of sand and $2 \%$ of cement), and the same gravel mixtures with 2,4 and $6 \%$ cement and hydrated lime. Laboratory tests were performed to characterize the soil, compaction in the Intermediate Proctor energy, expansion, California Bearing Ratio, unconfined compression and dynamic triaxial mixtures molded in optimum compaction condition for three curing times ( 0,7 and 28 days). The resilient moduli results were evaluated by numerical analysis using KENLAYER software. To complement the analysis of the resistance results, $\mathrm{X}$-ray diffraction and scanning electron microscopy tests were carried out. The results show that for the studied soil, the chemical stabilization with lime contributed little to the increase of strength parameters, but the use of cement showed greater potential use. Differences on behavior observed in unconfined compression tests and dynamic triaxial were explained by changes that occur in the microstructure during the stabilization process. Finally, it was clear that the tropical soil stabilization process is complex, with over current mechanical tests, such as dynamic triaxial, and unconventional parameters for pavement soil analysis, such as wa- 
ter/cement ratio and porosity, should be analyzes incorporated in order to obtain more consistent results.

Keywords: Laboratory tests. Soils stabilization. Soil-lime. Soil-cement. Asphalt pavement.

\section{INTRODUÇÃO}

A malha rodoviária de um país é muito representativa de suas condições de desenvolvimento, além de ser um fator decisivo para que isso aconteça. No Brasil, $61 \%$ do transporte de cargas e mais de $90 \%$ dos deslocamentos de passageiros são feitos pelo modal rodoviário [1], tornando a qualidade das rodovias importante para o desenvolvimento econômico do país.

No Brasil, as rodovias são predominantemente compostas por pavimentos flexíveis ou asfálticos, em virtude do seu custo inicial e da facilidade construtiva em relação aos outros tipos de pavimentos. A estrutura é complexa, sendo constituída por camadas com diferentes funções que interagem entre si para garantir as características estruturais indispensáveis ao projeto. $\mathrm{O}$ que diferencia e garante as propriedades necessárias a cada uma dessas camadas são: disposição, espessura e materiais constituintes. SENÇO [2] cita que alguns materiais bastante utilizados nas camadas de base dos pavimentos asfálticos são os aglomerantes, tais como a cal, cimentos e pozolanas, usados de acordo com o projeto ou a disponibilidade no local. Já o solo granular ou a brita são indispensáveis por serem utilizados em grande quantidade na estrutura do pavimento e influenciam em uma gama de características.

Os solos lateríticos predominante na região do Centro-Oeste são finos e ricos em ferro e alumínio, mas podem não ser adequados para a base de vias de alto volume de tráfego, por apresentar capacidade suporte inferior à normalmente exigida. Os materiais empregados com essa finalidade, geralmente, são os mais granulares constituídos de pedra britada ou cascalho. No entanto, a exploração dessas jazidas envolve custos elevados e problemas ambientais. No caso do estado de Goiás, o cascalho laterítico tradicionalmente utilizado nas obras de pavimentação já foi bastante explorado e não apresenta mais qualidade e resistência satisfatória, sendo que sua estabilização química surge como uma das possíveis soluções para viabilizar o seu uso.

As variações mineralógicas presentes nos solos tropicais são maiores do que nos solos de outras regiões. É importante considerar a constituição mineralógica dos grãos e partículas dos solos em suas propriedades e comportamento. Nos solos superficiais lateríticos, o quartzo é encontrado com muita frequência, principalmente nas frações de areia e pedregulho. Esse mineral tem como características: aumento da resistência à compressão e do módulo de elasticidade, alta estabilidade química, rápida reação somente com o ácido fluorídrico e dissolução lenta durante o processo de laterização. Além disso, outros minerais resistentes ao intemperismo podem existir nesses solos, dos quais destacam os minerais pesados como a magnetita e ilmenita [3].

A estabilização química visa a mistura de solos da região com aditivos para serem empregados nas camadas dos pavimentos, de maneira que se estabeleça a capacidade e a durabilidade estrutural das camadas. No processo de estabilização de solos, os aditivos comumente utilizados são a cal, cinzas de cal e cimento, que geram respostas físicas relacionadas com os componentes ativos do solo, principalmente os argilominerais. As estruturas dos solos naturais variam muito e podem influenciar os resultados da estabilização. Os solos vermelho-escuros geralmente intemperizados e os ácidos constituídos por caulinita e óxidos de ferro hidratados, que exibem uma fração fina e estrutura fraca, são rapidamente pulverizados ao serem misturados, resultando em uma maior homogeneidade. Trabalhos já publicados mostraram, por exemplo, que a trabalhabilidade dos solos argilosos ativos localizados na região Oeste de Nova Gales do Sul, na Austrália, foi melhorada com a adição de cal [4] e que solos podzólicos estudados por CROFT [5] apresentaram estabilização mais eficaz com cal, pelo fato do solo conter grande quantidade de argilominerais expansivos. Já para a estabilização com cimento, o autor constatou ser mais adequada com solos com baixo teor de argila e para algumas lateritas com textura granular, livre de argilominerais expansivos. Isso pode ser explicado pelo fato de que o cimento interage melhor com solos granulares que pulverizam mais facilmente, sendo que quando o teor de finos e a plasticidade aumentam, torna-se mais difícil obter uma granulometria uniforme.

Os fatores que influenciam as interações entre solo e cal incluem grau de intemperismo, $\mathrm{pH}$ do soloágua, concentração dos cátions de base, concentrações alumina-sílica, teor de matéria orgânica e de sulfatos solúveis existentes no solo. As duas fases que ocorrem no sistema de solo-cal envolvem primeiramente as reações de trocas iônicas e aglomeração-floculação, que ocorre em todos os solos com granulometria fina. Com as mudanças de textura causadas por essas reações dentro do solo, a estabilidade da resistência e a umidade são melhoradas, refletindo em uma trabalhabilidade melhor e redução da expansão. Já as reações pozolânicas incidem no ganho de resistência à longo prazo e são afetadas pela mineralogia da fração de argila que desenvolvem uma matriz cimentada entre as partículas dos solos, resultando em silicatos de cálcio hidratados (CSH) e aluminatos de cálcio hidratados (CAH) [6]. 
Segundo BELL [7], ao adicionar cal em um solo argiloso ocorre imediatamente alteração das propriedades do solo por meio das trocas catiônicas entre os íons metálicos associados à superfície das partículas dos argilominerais com dupla camada no meio hidratado, que são modificados pelos íons de cálcio presente na cal. Ao alterar a carga elétrica dos argilominerais, aparece a tendência de atrair mais as outras partículas para formar flocos, processo conhecido como floculação. $\mathrm{O}$ aumento do período de cura contribui para que as ligações entre as partículas ocorram, aumentando a resistência do solo. Como produtos da reação da argila com a cal, os silicatos de cálcio formam, em ambientes alcalinos e em pequenas quantidades, as fases de alumínio de cálcio hidratado $\left(\mathrm{C}_{4} \mathrm{AH}_{13}\right.$ e $\mathrm{C}_{3} \mathrm{AH}_{6}$, no caso de temperatura elevada) e alumínio silicato de cálcio $\left(\mathrm{C}_{2} \mathrm{ASH}_{8}\right)$, principalmente quando as argilas cauliníticas são tratadas com cal [8]. Esse processo químico que ocorre, enrijece os compostos formados durante a cura e pode continuar durantes meses [8].

CASANOVA [9] descreve que os minerais iniciais são mais organizados estruturalmente nas reações pozolônicas que envolvem os argilominerais, tem energia superficial menor (de 0,5 a 2 cal.g), são hidratados e formados à temperatura e pressão ambientes, sendo mais estáveis. Nesse caso, a velocidade das reações químicas é menor do que as que ocorrem na hidrólise do cimento, provocando um aumento gradual da resistência mecânica e perdura por um período muito longo.

$\mathrm{Na}$ estabilização química de solos com cimento, a quantidade de cimento acrescentada pode ser pequena, porém suficiente para aprimorar as propriedades de engenharia do solo e melhorar as trocas catiônicas da argila. Os solos estabilizados com cimento podem ter diminuição da plasticidade; decréscimo da expansão do volume ou compressibilidade e aumento da resistência. Em alguns solos, com grande afinidade por água como argila, turfa e solos orgânicos, o processo de hidratação pode ser retardado devido o teor de umidade ser insuficiente, afetando a resistência final [10].

HORPIBULSUK et al. [11] observaram que a resistência desenvolvida com o acréscimo de cimento para um teor de água específico é classificada em três zonas: ativa, inerte e deterioração. Na primeira zona, constatou para os teores de cimento entre $0-10 \%$, que o volume dos poros menores que 0,1 micrômetros diminuiu significativamente com o acréscimo desse aditivo por causa do aumento dos produtos de cimento. À medida que o teor aumenta, o contato do cimento com os grãos também aumenta, provocando o endurecimento. Na zona inerte para teores entre $11-30 \%$, tanto a granulometria quanto os produtos formados não mudaram muito com o acréscimo do cimento, ocorrendo ligeira mudança na resistência. Na zona de deterioração, foi verificada que a água não foi adequada para hidratação devido ao excesso de absorção do elevado teor de cimento (acima de 30\%). Consequentemente, com o aumento do teor de cimento, os produtos cimentíceos e a resistência das misturas diminuíram. Com a incorporação adequada do aditivo, JARITNGMAN et al. [12] ressaltam que as propriedades do solo laterítico podem ser aprimoradas. O mecanismo de cimentação ocorre com o acréscimo de água na mistura de solo e cimento, semelhante à estabilização com cal devido à formação de aluminatos e silicatos hidratados, reduzindo a plasticidade do solo e, no caso da existência de uma significativa fração de argila, tem efeito positivo, ocasionando o aumento da resistência do solo.

Este trabalho tem como objetivo comparar o comportamento mecânico dos materiais de base (mistura de cascalho laterítico, areia e cimento) definidos para o projeto de duplicação da rodovia GO-080 (trecho entre Nerópolis e entroncamento da BR-153) com esse mesmo cascalho estabilizado com cimento ou com cal, dando ênfase nos parâmetros obtidos em ensaios de laboratório.

\section{MATERIAIS E MÉTODOS}

A seguir, é apresentada a rodovia onde o estudo foi realizado bem como os materiais selecionados para a pesquisa e a descrição dos ensaios laboratoriais realizados.

\subsection{Seleção da rodovia}

A rodovia GO-080 (trecho entre Nerópolis e entroncamento da BR-153) foi selecionada para o estudo em comum acordo entre as instituições participantes da pesquisa. No relatório de projeto disponibilizado pela Agência Goiana de Transportes e Obras (AGETOP), foi determinado que a estrutura do pavimento seria constituída por sub-base granular com $20 \mathrm{~cm}$ de espessura, base com $20 \mathrm{~cm}$ de espessura composta de $78 \%$ de cascalho argiloso, $20 \%$ de areia e $2 \%$ de cimento Portland (CP II-Z-32) e revestimento do tipo concreto betuminoso usinado a quente (CBUQ) com $5 \mathrm{~cm}$ de espessura. O subleito era composto de solo argiloso com Índice de Suporte Califórnia (ISC) médio de 7\% quando compactado na energia Proctor normal.

Para a definição dos parâmetros de projeto dos materiais empregados na camada de base do pavimento foram escolhidas jazidas de solos granulares localizadas próximas dessa rodovia. Os materiais foram coletados e executados os seguintes ensaios pela AGETOP: granulometria, limite de plasticidade e liquidez, compactação (nas energias Proctor iguais a 26, 40 e 55 golpes) e ISC, de acordo com as normas do Departa- 
mento Nacional de Infraestrutura de Transportes (DNIT). Com o intuito de atender as exigências do projeto de pavimentação, o material de base foi misturado com areia para controlar a plasticidade e cimento com diferentes teores até se alcançar as especificações técnicas vigentes.

\subsection{Materiais}

Foram realizadas coletas de amostras do cascalho na jazida localizada nas coordenadas geográficas $16^{\circ} 11^{\prime} 46^{\prime \prime}$ Sul (latitude) e 49¹1'26" Oeste (longitude), no município da cidade Ouro Verde de Goiás. Conforme apresentado na Figura 1, a jazida de cascalho com laterita amarela está situada perto da GO-433 e aproximadamente a 24,200 km da rodovia GO-080. Esse material foi aplicado na camada de base ao longo de 19,284 km para a duplicação da GO-080.

A metodologia de coleta do material foi realizada de acordo com o procedimento do DNER PRO 003 [13]. Foram coletados aproximadamente $1800 \mathrm{~kg}$ do cascalho, aleatoriamente, em diferentes pontos da jazida e $100 \mathrm{~kg}$ da areia artificial fornecida por uma empresa local. Em seguida, os materiais foram armazenados em sacos plásticos, identificados e transportados para o Laboratório de Geotecnia da Escola de Engenharia Civil e Ambiental da UFG.

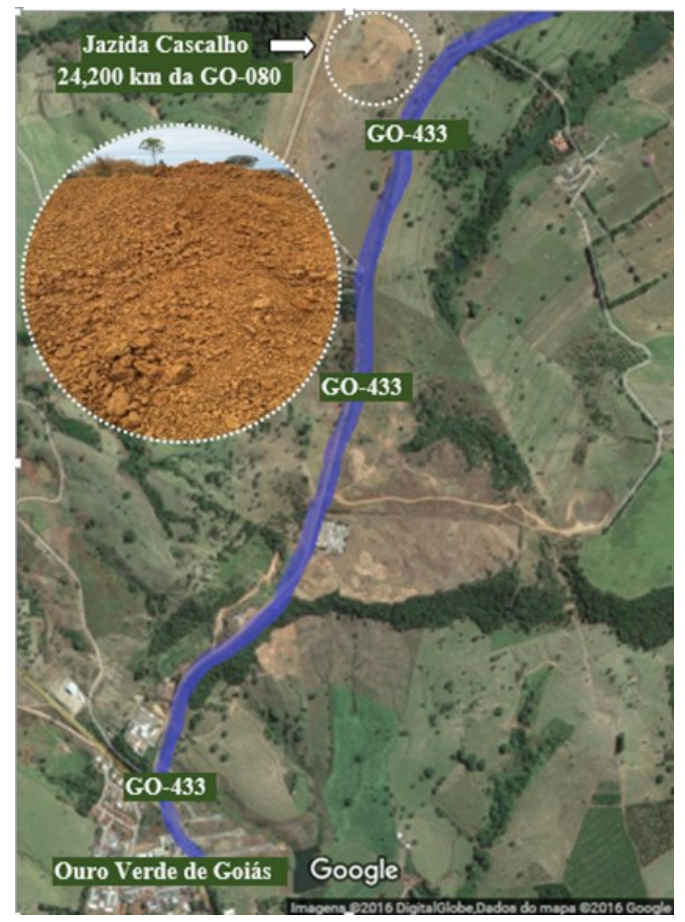

Figura 1: Localização da jazida do cascalho laterítico em estudo (Modificado de GOOGLE MAPS [14]).

Para as misturas com cimento, foi utilizado o mesmo tipo de cimento empregado na obra, o CP-II-Z32 e suas características fornecidas pelo fabricante estão apresentadas na Tabela 1 . Na análise das misturas com cal, foi utilizada a cal hidratada do tipo CH-III, com características químicas fornecidas pelo fabricante apresentadas na Tabela 2 .

Tabela 1: Características do cimento Portland.

\begin{tabular}{l|c|c}
\hline PARÂMETROS & VALORES & ESPECIFICAÇÃO \\
\hline Fração passante \# 200 (\%) & 1,1 & $\leq 12,0$ \\
\hline Fração passante \# 325 (\%) & 7,6 & $\geq 60$ \\
\hline Início de pega (min.) & 187 & $\leq 600$ \\
\hline Fim de pega (min.) & 250 & $\geq 20,0$ \\
\hline Resistência à compressão - 7 dias (MPa) & 35,0 & $\geq 32,0$ \\
\hline Resistência à compressão -28 dias (MPa) & 40,4 & $\leq 6,5$ \\
\hline MgO (\%) & 3,1 & $\leq 4,0$ \\
\hline SO $(\%)$ & 2,4 & $\leq 6,5$ \\
\hline Perda ao fogo média (\%) & 4,8 & $\leq 6,0$ \\
\hline Resíduo insolúvel (\%) & 6,3 & \\
\hline
\end{tabular}


Tabela 2: Características químicas da cal.

\begin{tabular}{l|c|c}
\hline PARÂMETROS & VALORES (\%) & ESPECIFICAÇÃO (\%) \\
\hline $\mathrm{SiO}_{2}$ & 2,79 & $<10,0$ \\
\hline $\mathrm{Al}_{2} \mathrm{O} 3$ & 0,54 & - \\
\hline $\mathrm{Fe}_{2} \mathrm{O} 3$ & 0,39 & - \\
\hline $\mathrm{CaO}$ (total) & 55,09 & - \\
\hline $\mathrm{MgO}$ & 12,82 & - \\
\hline $\mathrm{SO}_{3}$ & 0,25 & $\leq 13,0$ \\
\hline $\mathrm{CO}_{2}$ & 12,29 & $\leq 4,0$ \\
\hline $\mathrm{Cao} / \mathrm{H}$ & 0,88 & $<15,0$ \\
\hline Óxidos N/H & 12,82 & $>88,0$ \\
\hline $\mathrm{C}+\mathrm{M}(\mathrm{OT})$ & 91,32 & \\
\hline
\end{tabular}

Os estudos de dosagem com o cascalho empregado na camada de base da rodovia GO-080 abrangeram misturas com cimento e cal com o intuito de comparar essas misturas com a utilizada na obra ( $78 \%$ cascalho $+20 \%$ areia $+2 \%$ cimento). Os teores determinados para as dosagens das misturas de cascalho com cimento e cascalho com cal foram de $2 \%, 4 \%$ e $6 \%$, visando atender critérios técnicos e econômicos. Esses teores foram analisados em função da porcentagem de peso em relação à mistura total de cada amostra estudada, para permitir uma avaliação comparativa do processo de estabilização para o solo em questão, sem que ocorresse impacto significativo nos custos.

\subsection{Programa Experimental}

No laboratório, as amostras foram preparadas de acordo com as normas do DNER ME 041 [15] e NBR 6457 [16]. Todo o material coletado foi homogeneizado após a secagem ao ar livre para obter uma amostra total representativa. $\mathrm{O}$ cascalho foi peneirado e separado em sacos de acordo com a granulometria (fração passante na $19 \mathrm{~mm}$ e passante na $4,8 \mathrm{~mm}$ ) para serem utilizados na preparação das amostras dos ensaios. Sendo que a fração retida na peneira de $19 \mathrm{~mm}$ foi de aproximadamente $19 \%$ do total de material coletado. Em seguida, foram realizados os ensaios de caracterização física, os ensaios de compactação e mecânicos com o cascalho na umidade higroscópica (em média de 1,0 a 2,0\%), conforme o planejamento experimental descrito a seguir.

\subsubsection{Caracterização física}

Após a coleta e preparação das amostras, foram executados os ensaios de caracterização geotécnica do solo natural, de acordo com os métodos de ensaios descritos a seguir:

- Análise granulométrica de solos por peneiramento e sedimentação, conforme norma do DNER ME 051[17]. No ensaio de sedimentação, as amostras foram analisadas com e sem o uso do defloculante hexametafosfato de sódio. Com as misturas não foi realizado o ensaio de sedimentação devido à influência química tanto da cal quanto do cimento na estabilidade dos agregados;

- $\quad$ Limite de liquidez, segundo a norma do DNER ME 122 [18];

- $\quad$ Limite de plasticidade, conforme a norma do DNER ME 082 [19];

- Massa específica de grãos de solo que passam na peneira de 4,8 mm, segundo a NBR 6508 [20];

- Massa específica e absorção de pedregulhos retidos na peneira de 4,8 mm, conforme a NBR 6458 [21].

Com os resultados obtidos, o material foi classificado conforme as classificações da Transportation Research Board (TRB) e Sistema Unificado de Classificação de Solos (SUCS).

\subsubsection{Compactação, Expansão e ISC}

Os ensaios de compactação, expansão e Índice de Suporte Califórnia (ISC) foram realizados em amostras deformadas com a fração passante na peneira de $19 \mathrm{~mm}$ do cascalho natural utilizado na rodovia.

Foram moldadas cinco amostras de $7 \mathrm{~kg}$ para cada teor estudado, conforme o método de ensaio de compactação do DNIT ME 164 [22], para determinação das curvas de compactação (peso específico aparente seco $\mathrm{x}$ teor de umidade) na energia igual à empregada na compactação da camada de base da obra (Proctor intermediário). Neste estudo, optou-se por padronizar o procedimento de moldagem dos corpos de prova tanto no ensaio de compactação quanto de compressão simples e triaxial dinâmico. Sendo assim, destaca-se que para as misturas de cascalho com cal, o tempo entre homogeneização dos materiais e a compactação foi de uma hora, conforme especificado na norma americana ASTM D 5102 [23]. Para as outras amostras (cascalho 
sem estabilização e misturas com cimento), a moldagem dos corpos de prova foi realizada imediatamente após a homogeneização com água, de acordo com a norma do DNER ME 202 [24].

Terminadas as moldagens dos corpos de prova, os moldes foram imersos em água durante quatro dias e anotadas as leituras das expansões ocorridas em intervalos de $24 \mathrm{em} 24$ horas. Em seguida, cada molde com corpo de prova foi ensaiado à penetração para obter o ISC, segundo a norma do DNER ME 049 [25].

\subsubsection{Compressão Simples}

A moldagem das amostras de cascalho com cimento foi realizada conforme o método de ensaio do DNER ME 202 [24], em moldes cilíndricos de $10 \mathrm{~cm}$ de diâmetro. Para isso, foi necessário realizar o escalpo da amostra de partículas superiores a $9,5 \mathrm{~mm}$ de diâmetro. Foram moldados três corpos de prova para cada teor em estudo, com referência nos parâmetros de peso específico aparente seco máximo $\left(\gamma_{\text {dmáx }}\right)$ e umidade ótima $\left(w_{\text {ót }}\right)$ obtidos nos ensaios de compactação para a energia Proctor intermediária.

O conjunto (molde + corpo de prova) foi pesado e, em seguida, o corpo de prova foi removido do molde para determinar as suas dimensões. Os corpos de prova foram curados por um período de 7 e 28 dias em câmara úmida, com temperatura e umidade controladas: temperatura de $23^{\circ} \pm 2{ }^{\circ} \mathrm{C}$ e umidade relativa do ar superior a 95\%. Para esse procedimento foi utilizada a câmara úmida do Laboratório de Inovação Tecnológica em Construção Civil (LABITECC) da Escola de Engenharia Civil e Ambiental da UFG.

Ao final do período de cura, as amostras foram rompidas, sendo que dois corpos de prova de cada mistura com cimento foram ensaiados sem imersão e um corpo de prova foi imerso em água por 4 horas, de acordo com a norma do DNER ME 201 [26]. Esse procedimento teve a finalidade de comparar os resultados tanto para as misturas consideradas melhoradas com cimento (com $2 \%$ ) quanto para as de solo-cimento (com 4 e $6 \%)$.

Já para as misturas constituídas de cascalho com cal, a moldagem dos corpos de prova e os procedimentos para realização do ensaio de compressão simples foram executados de acordo com a norma americana ASTM D 5102 [23]. Diferentemente das amostras de cascalho-cimento, a mistura homogeneizada de cascalho-cal foi deixada em repouso por uma hora antes da compactação e a cura foi do tipo seca realizada na temperatura ambiente para os mesmos períodos de cura do cascalho com cimento. Para isso, os corpos de prova foram selados com papel filme PVC e colocados em sacos plásticos vedados para evitar a perda da umidade, sendo que após a realização do ensaio foi verificada a umidade ao final do período de cura. Como essa norma não preconiza a imersão dos corpos de prova antes da ruptura, esse procedimento não foi executado.

No ensaio utilizou-se a mesma prensa empregada no ensaio de ISC, com velocidade de aplicação de carga de aproximadamente igual a $1,20 \mathrm{~mm} / \mathrm{min}$. Para a análise dos resultados, os valores de resistência máxima para cada dosagem foram determinados pela média das resistências de dois corpos de prova, sendo que esses valores não poderiam diferir em mais ou menos $10 \%$ da média.

\subsubsection{Triaxial Dinâmico}

O ensaio triaxial de carga repetida para obtenção do módulo de resiliência (MR) foi realizado no Laboratório de Asfalto da Escola de Engenharia Civil e Ambiental da UFG. Os ensaios foram realizados numa prensa UTM-30 (Figura 2a) de acordo com a norma do DNIT ME 134 [27], sendo que nesse equipamento os medidores das deformações são fixados no corpo de prova (Figura $2 b$ ).

A norma utilizada descreve os métodos para obter os valores do MR dos solos para várias tensões aplicadas (sequência de 18 pares de tensões). Esse ensaio prevê o comportamento mecânico do solo em termos de deformabilidade resiliente (elástica). Primeiramente, as amostras foram compactadas na $\mathrm{w}_{\text {ót }} \mathrm{e}$ com $\gamma_{\text {dmáx }}$ em moldes cilíndricos diferentes dos anteriores, com dimensões de $10 \mathrm{~cm}$ de diâmetro e $36 \mathrm{~cm}$ de altura, com a finalidade de obter o corpo de prova com $20 \mathrm{~cm}$ de altura final.

Os materiais homogeneizados foram moldados dentro do cilindro de $36 \mathrm{~cm}$ de altura, e em seguida, foi extraído o corpo de prova do molde. Assim, foi necessário calcular a influência da energia intermediária na quantidade de golpes aplicados para obter a mesma energia utilizada nos ensaios de ISC e compressão simples. Para tanto, foram moldados corpos de prova cilíndricos em 3 camadas, com aplicação de 19 golpes por camada. Para as análises, foram moldados dois corpos de prova para cada mistura e tempo de cura $(0,7 \mathrm{e}$ 28 dias). 


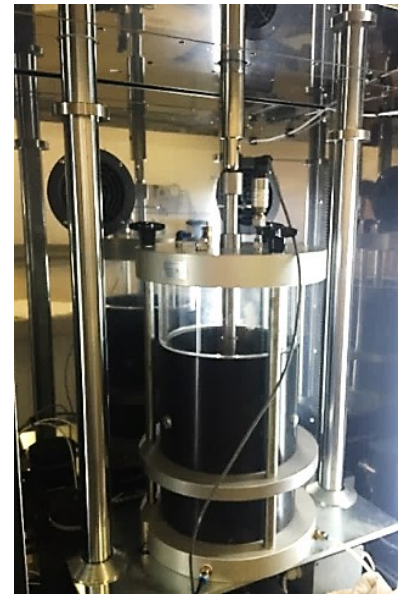

(a)

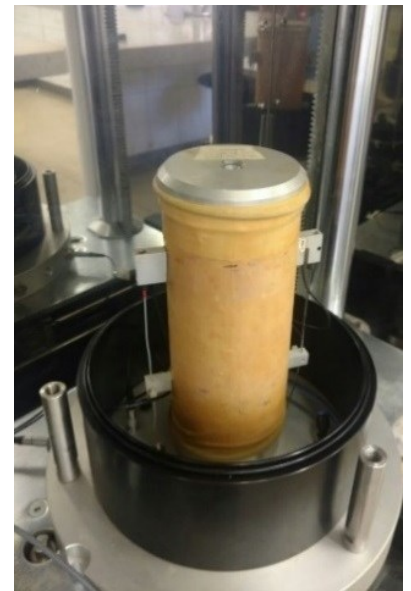

(b)

Figura 2: (a) Equipamento triaxial dinâmico, UTM-30; (b) Montagem do corpo de prova.

\subsubsection{Análise Mineralógica e Microestrutural}

Para identificar os minerais existentes nas misturas estudadas, foram realizados ensaios de difratometria de raios-X (DRX) no Centro Tecnológico de Furnas, localizado em Aparecida de Goiânia-GO. Esses ensaios foram realizados nas amostras de cascalho natural e nas seguintes misturas: $78 \%$ cascalho $+20 \%$ areia $+2 \%$ cimento, cascalho $+2 \%$ cimento, cascalho $+6 \%$ cimento, cascalho $+2 \%$ cal e cascalho $+6 \%$ cal. Para otimizar os ensaios, optou-se por não realizar avaliações com as amostras compostas com $4 \%$ de aditivo (cimento e cal), assumindo-se que seus comportamentos seriam semelhantes aos das misturas com $6 \%$.

Primeiramente, essas amostras foram submetidas à moagem em gral de ágata até obtenção de $100 \%$ do material passante na peneira $0,043 \mathrm{~mm}$, com o objetivo de obter uma fração representativa de granulação bem fina. Em seguida, o material foi analisado no Difratômetro de Raios-X pelo Método do Pó NãoOrientado (Análise Integral) sob voltagem $40 \mathrm{KV}$ e amperagem de $30 \mathrm{~mA}$, em sistema $\theta / 2 \theta$, com velocidade de varredura de $0,05^{\circ} / \mathrm{seg}$, de $2^{\circ}$ a $70^{\circ} 2 \theta$. A fonte de energia utilizada foi um filamento de tungstênio (cátodo) e o tubo de raios $\mathrm{X}$ foi o de cobalto (ânodo), com o intuito de diminuir a interferência dos minerais com existência de ferro em sua composição química.

Para avaliar a microestrutura das misturas, foram executados ensaios de Microscopia Eletrônica de Varredura (MEV) no Centro Regional para o Desenvolvimento Tecnológico e Inovação (CRTI) da UFG. Os ensaios foram realizados nas amostras de cascalho natural e nas seguintes misturas: $78 \%$ cascalho $+20 \%$ areia $+2 \%$ cimento, cascalho $+2 \%$ cimento, cascalho $+4 \%$ cimento, cascalho $+6 \%$ cimento, cascalho $+2 \%$ cal, cascalho $+4 \%$ cal e cascalho $+6 \%$ cal. Essas amostras foram fixas com a fita adesiva de carbono sobre o porta amostras de alumínio e recobertas com ouro (material condutor). As análises foram realizadas em um MEV, modelo JEOL JSM-IT300.

Para ambos os ensaios foram preparadas as amostras nas mesmas condições de compactação empregadas para o ensaio de compressão simples. Com o intuito de analisar a influência da estabilização química ao longo do tempo e para otimizar a realização desses ensaios especiais, inicialmente optou-se por avaliar as amostras após 28 dias de cura. Porém, devido à disponibilidade dos equipamentos, as amostras foram ensaiadas com 31 dias de cura para o ensaio de MEV e 21 dias para o ensaio DRX.

\section{RESULTADOS E DISCUSSÕES}

A seguir, são apresentados os resultados experimentais das misturas estudadas na pesquisa.

\subsection{Ensaios de Caracterização}

Os ensaios de análise granulométrica e limites de Atterberg foram realizados com o cascalho natural e a areia utilizada na dosagem da obra com o intuito de analisar suas características e classificações de forma separada. As propriedades físicas e a distribuição granulométrica das frações de cascalho estão apresentadas na Tabela 3.

Conforme observado, o cascalho natural estudado foi classificado como um pedregulho siltoso (GM) do tipo A-2-6 de acordo com as classificações SUCS e TRB, respectivamente. O cascalho apresenta índice de 
plasticidade inferior a $15 \%$, mas com argila ativa. Como o ensaio de sedimentação é realizado com a fração passante na peneira de 2,00 mm, foi possível avaliar as agregações presentes nas partículas ao adicionar o defloculante. Assim, verifica-se a tendência de agregação da fração fina do cascalho, pois no ensaio sem defloculante as frações areia e silte são maiores do que as observadas para o ensaio com defloculante, sendo que de fato, parte desses teores é constituída de partículas agregadas de argila laterítica. Com o uso do defloculante, essas agregações são desfeitas causando redução nos teores de areia e silte e o aparecimento de argila.

Tabela 3: Propriedades do cascalho laterítico.

\begin{tabular}{|c|c|c|}
\hline \multirow{2}{*}{ PARÂMETROS } & \multicolumn{2}{|c|}{ CASCALHO NATURAL } \\
\hline & C. DEF. & S. DEF. \\
\hline Pedregulho (\%) & 83,25 & 83,25 \\
\hline Areia $(\%)$ & 4,49 & 11,01 \\
\hline Silte $(\%)$ & 3,56 & 5,74 \\
\hline Argila (\%) & 8,71 & 0,00 \\
\hline Limite Liquidez (\%) & \multicolumn{2}{|r|}{40} \\
\hline Limite Plasticidade (\%) & \multicolumn{2}{|r|}{26} \\
\hline Índice Plasticidade (\%) & \multicolumn{2}{|r|}{14} \\
\hline Índice de Atividade (\%) & \multicolumn{2}{|r|}{1,61} \\
\hline Classificação SUCS & \multicolumn{2}{|r|}{ GM } \\
\hline Classificação TRB & \multicolumn{2}{|r|}{ A-2-6 } \\
\hline Massa Específica fração passante na peneira $4,8 \mathrm{~mm}\left(\mathrm{~g} / \mathrm{cm}^{3}\right)$ & \multicolumn{2}{|r|}{2,95} \\
\hline Massa Específica dos grãos retidos na peneira $4,8 \mathrm{~mm}\left(\mathrm{~g} / \mathrm{cm}^{3}\right)$ & \multicolumn{2}{|r|}{2,91} \\
\hline Absorção de água (\%) & \multicolumn{2}{|r|}{6,26} \\
\hline
\end{tabular}

Obs.: SUCS = Sistema Unificado de Classificação de Solos; GM = Pedregulho Siltoso; TRB = Transportation Research Board;C. DEF. $=$ Com Defloculante; S. DEF. $=$ Sem Defloculante.

A areia utilizada na dosagem da obra foi classificada como mal graduada (SP) de acordo com a classificação SUCS e tem quantidade significativa de areia média e grossa, sendo a maior parte compreendida diâmetro entre os diâmetros de $0,06 \mathrm{~mm}$ e $2,00 \mathrm{~mm}$. Os dados obtidos da caracterização física estão mostrados na Tabela 4. Apesar da areia não apresentar plasticidade, na análise granulométrica com o uso do defloculante foi detectada a presença das frações argila e silte, fato que provavelmente está relacionado à contaminação da areia com o solo laterítico encontrado no local de coleta. Conforme já explicado, a parte fina do solo laterítico apresenta ligações estáveis na presença de água tornando o solo mais agregado. Ao utilizar o defloculante, essas agregações são desfeitas e são registrados teores de finos no material.

Tabela 4: Propriedades da areia.

\begin{tabular}{|c|c|c|}
\hline \multirow{2}{*}{ PARÂMETROS } & \multicolumn{2}{|c|}{ AREIA ARTIFICIAL } \\
\hline & C. DEF. & S. DEF. \\
\hline Pedregulho (\%) & 2,76 & 2,76 \\
\hline Areia grossa $(\%)$ & 38,61 & 36,14 \\
\hline Areia média $(\%)$ & 41,82 & 42,12 \\
\hline Areia fina $(\%)$ & 13,18 & 18,99 \\
\hline Silte $(\%)$ & 3,03 & 0,00 \\
\hline Argila (\%) & 0,59 & 0,00 \\
\hline Limite Liquidez (\%) & \multicolumn{2}{|c|}{ - } \\
\hline Limite Plasticidade (\%) & \multicolumn{2}{|c|}{-} \\
\hline Índice Plasticidade (\%) & \multicolumn{2}{|c|}{ NP } \\
\hline Classificação SUCS & \multicolumn{2}{|c|}{ SP } \\
\hline Classificação TRB & \multicolumn{2}{|c|}{ A-3 } \\
\hline Massa Específica fração passante na peneira $4,8 \mathrm{~mm}\left(\mathrm{~g} / \mathrm{cm}^{3}\right)$ & \multicolumn{2}{|c|}{2,66} \\
\hline
\end{tabular}

Obs.: SUCS = Sistema Unificado de Classificação de Solos; SP = Areia mal graduada; NP = Não plástico; TRB = Transportation Research Board; C.DEF. = Com Defloculante; S. DEF. $=$ Sem Defloculante.

\subsection{Compactação, Expansão e ISC}

Na Figura 3 são apresentadas as curvas de compactação obtidas para o cascalho natural (C) e para as misturas avaliadas com areia (A), cimento (CI) e cal (CA). Com exceção da curva obtida para a mistura do cascalho com areia e $2 \%$ de cimento, as demais misturas apresentaram curvas mais baixas e deslocadas para a direita em relação à curva obtida para o cascalho natural, ou seja, com menores valores de peso específico aparente seco máximo e maiores valores de umidade ótima. 
Ressalta-se que para obter as curvas de compactação para as misturas de cascalho-cimento, observouse maior dificuldade em atingir o ramo úmido. Pelo fato do cascalho laterítico ter graduação aberta (granulometria descontínua), com insuficiência de material fino para preencher os vazios entre as partículas maiores, observou-se dificuldade em adicionar mais que 14\% de água na mistura seca, devido essa quantidade de água ser excedente para homogeneização do material.

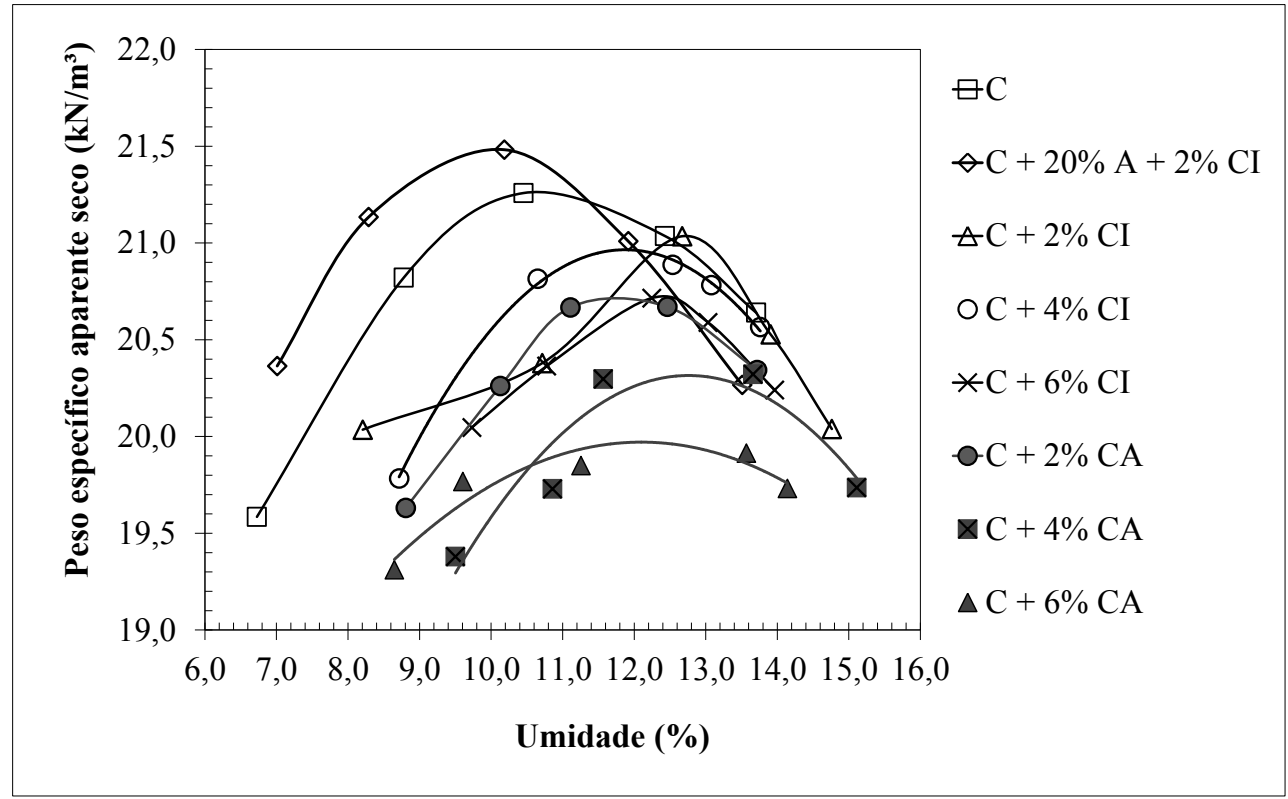

Figura 3: Curvas de compactação.

Na Tabela 5 está apresentado o resumo dos resultados encontrados a partir das curvas de compactação, como peso específico seco máximo e umidade ótima, e os respectivos valores de expansão, ISC, índice de vazios obtidos para cada mistura na umidade ótima. Observa-se que o peso específico aparente seco máximo foi maior para a mistura utilizada na obra, fato que está associado com o índice de vazios que consistem na melhor distribuição granulométrica [28]. Destaca-se que quando as partículas menores, nesse caso a fração areia, são adicionadas a uma estrutura com grãos maiores, no caso o cascalho, ocorre diminuição do índice de vazios e aumento do peso específico aparente seco até uma determinada relação entre a mistura de partículas menores com as maiores.

Tabela 5: Resultados obtidos nos ensaios de compactação, ISC, expansão, índice de vazios na umidade ótima.

\begin{tabular}{|c|c|c|c|c|c|c|c|c|}
\hline DOSAGEM & C & $\begin{array}{l}\mathrm{C}+20 \% \mathrm{~A}+ \\
2 \% \mathrm{Cl}\end{array}$ & $\mathrm{C}+2 \% \mathrm{Cl}$ & $\mathrm{C}+4 \% \mathrm{Cl}$ & $\mathrm{C}+6 \% \mathrm{Cl}$ & $\mathrm{C}+2 \% \mathrm{CA}$ & $C+4 \% C A$ & $\mathrm{C}+6 \% \mathrm{CA}$ \\
\hline AMOSTRA & 1 & 2 & 3 & 4 & 5 & 6 & 7 & 8 \\
\hline $\mathrm{w}_{\mathrm{ott}}(\%)$ & 11,1 & 9,8 & 12,7 & 11,7 & 12,4 & 11,7 & 12,7 & 12,6 \\
\hline$\gamma_{\mathrm{dmáx}}\left(\mathrm{kN} / \mathrm{m}^{3}\right)$ & 21,30 & 21,50 & 21,10 & 21,00 & 20,70 & 20,70 & 20,30 & 20,00 \\
\hline e & 0,37 & 0,36 & 0,38 & 0,39 & 0,41 & 0,41 & 0,44 & 0,46 \\
\hline $\mathrm{ISCW}_{\text {ót }}(\%)$ & 32 & 144 & 97 & 300 & 260 & 50 & 54 & 48 \\
\hline Expansão (\%) & 0,02 & 0,02 & 0,01 & 0,01 & 0,01 & 0,02 & 0,01 & 0,02 \\
\hline
\end{tabular}

Obs.: $\mathrm{C}=$ Cascalho; $\mathrm{A}=$ areia; $\mathrm{CI}=$ cimento; $\mathrm{CA}=\mathrm{cal} ; \mathrm{w}_{\mathrm{ót}}=$ umidade ótima; $\gamma_{\mathrm{dmáx}}=$ peso específico aparente seco máximo; e = índice de vazios; ISC = Índice de Suporte Califórnia.

A estabilização química juntamente com a granulométrica $(\mathrm{C}+20 \% \mathrm{~A}+2 \% \mathrm{CI})$ gerou uma mistura com melhor desempenho em relação à capacidade de carga do material ao comparar com os valores de ISC para a mistura com mesmo teor de cimento, mas sem areia $(\mathrm{C}+2 \% \mathrm{CI})$. No entanto, para maiores teores de cimento $(4 \%$ e $6 \%)$, em termos de ISC os valores foram maiores que as demais. $\mathrm{O}$ fato do valor de ISC ter sido maior para o teor de $4 \%$ do que para o de $6 \%$ pode indicar que existiria um teor ótimo de estabilizante para inserir no cascalho. No entanto, pelo fato do ensaio de ISC não ser o mais indicado para a definição da dosagem de misturas de solo-cimento, os resultados de outros devem ser avaliados para obter melhores conclusões.

Observa-se que com acréscimo de $2 \%$ de cal ocorreu um considerável aumento no valor do ISC em relação ao cascalho natural. Porém, com adição de maior teor $(6 \%)$, não houve ganho de resistência em rela- 
ção as misturas com 2 e $4 \%$ de cal, o que pode estar relacionado com a ausência ou pequena quantidade de alumínio disponível no solo para reagir com a cal. Para a determinação da porcentagem de cal a ser utilizada na estabilização para obter uma capacidade de suporte desejada, é indicado que em solos granulares varie o teor entre $2 \%$ a $5 \%$, enquanto para solos plásticos entre $5 \%$ e $10 \%$ após a realização de uma série de ensaios [29]. De acordo com o estudo de BELL [7] com solos argilosos, o ganho de resistência a curto prazo foi significativo para os teores ótimos de 4 e $6 \%$ de cal, sendo que argilominerais do tipo montmorilonita responderam melhor à estabilização com cal do que os argilominerais do tipo caulinita.

Dentre as misturas estudadas, apenas aquelas estabilizadas com cal não apresentaram parâmetros adequados para serem utilizadas como base de pavimentos para vias de elevado volume de tráfego, já que as normas brasileiras atuais exigem que o valor de ISC seja superior a 80\%. Porém, todas as misturas com cal poderiam ser empregadas na camada de sub-base, por apresentar valor de ISC superior a 30\% de acordo com as recomendações da norma do DER-SP ET- P00/005 [30]. Com relação à expansão, nenhum dos materiais estudados apresentou algum tipo de problema ou limitação.

No entanto, deve-se ressaltar que o ensaios de ISC é limitado para avaliar o comportamento mecânico de solos estabilizados quimicamente. O ideal é que ensaios como compressão simples e triaxial dinâmico sejam realizados para aprimoramento das análises. De qualquer forma, os resultados apresentados até o momento, mostram que o cascalho laterítico estudado já não atende as normas ainda vigentes no Brasil para ser utilizado como base de pavimento. Para esse tipo de solo, há indícios de que sua estabilização química com cimento gera ganhos mais significativos do que com a cal. Geralmente, ao incorporar somente cal em materiais com plasticidade baixa a média, os resultados não são satisfatórios, sendo necessário o acréscimo de pozolanas, como por exemplo, cinzas volantes para tornar o solo reativo e produzir as reações necessárias [31, 32].

\subsection{Compressão Simples}

As resistências à compressão simples (RCS) para as misturas com adição de cimento foram analisadas para as condições sem e com imersão em água no tanque por quatro horas, sem e com 7 e 28 dias de cura, conforme mostrado na Figura 4.

$\mathrm{Na}$ Figura 4, observa-se que para a mistura da obra $(\mathrm{C}+20 \% \mathrm{~A}+2 \% \mathrm{CI})$ ocorreu queda de resistência aos 28 dias para os ensaios realizados com e sem imersão. Vale ressaltar que o ensaio foi repetido para esse período de cura. Para explicar essa ocorrência, algumas análises foram realizadas. A primeira delas está relacionada com os dados apresentados nas Tabelas 6 e 7. No caso em questão, detectou-se que os valores de umidade dos corpos de prova ensaiados aos 28 dias foram superiores aos 7 dias e aos corpos de prova rompidos sem cura. Essa situação pode ter gerado a redução dos valores de resistência. Para a mistura da obra, verifica-se que durante a moldagem do corpo de prova, devido à heterogeneidade do material, os corpos de prova ficaram com porosidade entre 28 e $29 \%$, fato que permitiria a presença da água excedente na estrutura da amostra após a cura úmida. Outras questões como mineralogia e microestrutura das misturas também podem auxiliar no entendimento desses fatos. Ainda na Figura 4, verifica-se que para a mistura do cascalho com $2 \%$ de cimento $(\mathrm{C}+2 \% \mathrm{CI})$ o ganho de resistência ao longo do tempo não foi significativo. A partir de $4 \%$ de adição de cimento ao cascalho a resistência continuou aumentando ao longo do tempo, sendo que os melhores resultados foram obtidos para as amostras com $6 \%$ de cimento, tanto na situação com como sem imersão.

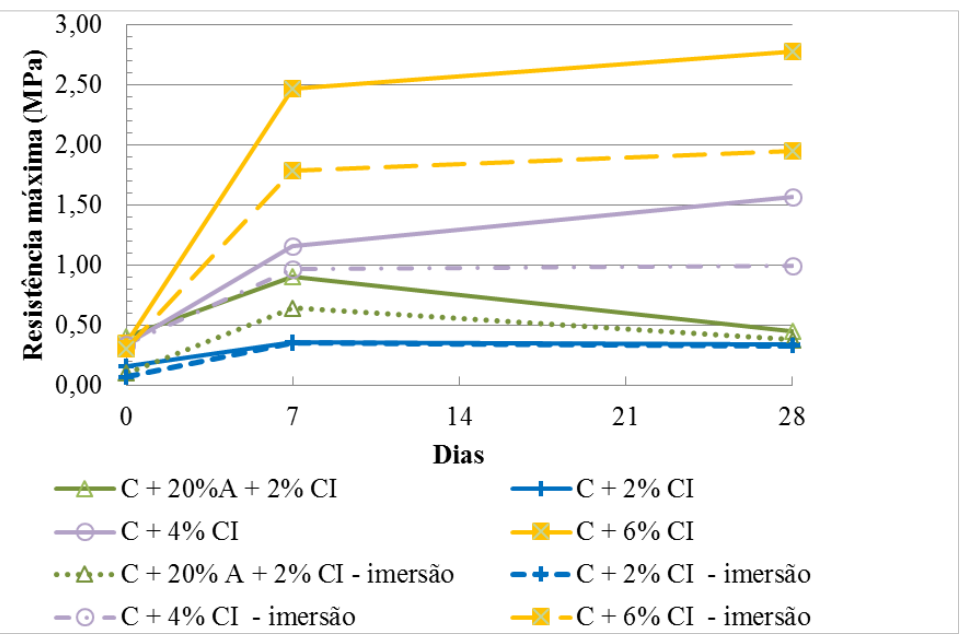

Figura 4: Comparação da RCS para as amostras cascalho-cimento (com e sem imersão). 
Tabela 6: Dados de moldagem e umidade após os períodos de cura das amostras de cascalho-cimento (sem imersão).

\begin{tabular}{|c|c|c|c|c|c|c|c|c|c|}
\hline \multicolumn{2}{|c|}{ PARÂMETROS } & \multicolumn{2}{|c|}{$\mathrm{C}+20 \% \mathrm{~A}+2 \% \mathrm{Cl}$} & \multicolumn{2}{|c|}{$\mathrm{C}+2 \% \mathrm{Cl}$} & \multicolumn{2}{|c|}{$\mathrm{C}+4 \% \mathrm{Cl}$} & \multicolumn{2}{|c|}{$\mathrm{C}+6 \% \mathrm{Cl}$} \\
\hline \multirow{6}{*}{ Sem cura } & CP & 2.1 & 2.2 & 3.1 & 3.2 & 4.1 & 4.2 & 5.1 & 5.2 \\
\hline & $\mathrm{W}_{\text {antes }}(\%)$ & 9,5 & 9,7 & 12,8 & 13,2 & 12,1 & 12,6 & 12,3 & 12,4 \\
\hline & $\mathrm{w}_{\text {depois }}(\%)$ & 9,2 & 9,7 & 12,3 & 12,4 & 11,8 & 11,9 & 12,2 & 12,4 \\
\hline & $\mathrm{e}$ & 0,38 & 0,38 & 0,42 & 0,41 & 0,44 & 0,43 & 0,43 & 0,43 \\
\hline & $\eta(\%)$ & 28 & 28 & 30 & 29 & 30 & 30 & 30 & 30 \\
\hline & GC (\%) & 98 & 98 & 97 & 99 & 97 & 97 & 98 & 99 \\
\hline \multirow{6}{*}{7 dias } & $\mathbf{C P}$ & 2.3 & 2.4 & 3.3 & 3.4 & 4.3 & 4.4 & 5.3 & 5.4 \\
\hline & $\mathrm{w}_{\text {antes }}(\%)$ & 9,3 & 9,6 & 12,8 & 12,5 & 11,7 & 11,6 & 12,5 & 12,1 \\
\hline & $\mathrm{w}_{\text {depois }}(\%)$ & 11,6 & 11,5 & 14,0 & 13,6 & 13,4 & 13,3 & 12,9 & 12,2 \\
\hline & $\mathrm{e}$ & 0,39 & 0,40 & 0,42 & 0,42 & 0,45 & 0,43 & 0,41 & 0,40 \\
\hline & $\eta(\%)$ & 28 & 28 & 29 & 29 & 31 & 30 & 29 & 29 \\
\hline & GC (\%) & 97 & 97 & 98 & 98 & 96 & 97 & 100 & 101 \\
\hline \multirow{6}{*}{28 dias } & $\mathbf{C P}$ & 2.5 & 2.6 & 3.5 & 3.6 & 4.5 & 4.6 & 5.5 & 5.6 \\
\hline & $\mathrm{w}_{\text {antes }}(\%)$ & 10,1 & 10,0 & 12,9 & 12,4 & 11,9 & 12,0 & 12,3 & 12,3 \\
\hline & $\mathrm{w}_{\text {depois }}(\%)$ & 13,5 & 13,2 & 14,9 & 14,3 & 15,0 & 14,5 & 13,7 & 13,1 \\
\hline & $\mathrm{e}$ & 0,41 & 0,39 & 0,41 & 0,40 & 0,44 & 0,42 & 0,42 & 0,39 \\
\hline & $\eta(\%)$ & 29 & 28 & 29 & 28 & 30 & 30 & 30 & 28 \\
\hline & GC (\%) & 96 & 98 & 98 & 100 & 97 & 97 & 99 & 102 \\
\hline
\end{tabular}

Obs.: $\mathrm{CP}=$ corpo de prova; $\mathrm{C}=$ Cascalho; $\mathrm{A}=$ areia; $\mathrm{CI}=$ cimento; $\mathrm{w}=$ umidade $; \mathrm{GC}=$ grau de compactação; $\mathrm{e}=$ índice de vazios; $\eta=$ porosidade.

Tabela 7: Dados de moldagem e umidade após imersão das amostras de cascalho-cimento (com imersão).

\begin{tabular}{|c|c|c|c|c|c|}
\hline \multicolumn{2}{|c|}{ PARÂMETROS } & $\mathrm{C}+20 \% \mathrm{~A}+2 \% \mathrm{Cl}$ & $\mathrm{C}+2 \% \mathrm{Cl}$ & $\mathrm{C}+4 \% \mathrm{Cl}$ & $\mathrm{C}+6 \% \mathrm{Cl}$ \\
\hline \multirow{6}{*}{ Sem cura } & $\mathbf{C P}$ & 2.7 & 3.7 & 4.7 & 5.7 \\
\hline & $\mathrm{w}_{\text {antes }}(\%)$ & 9,6 & 12,6 & 12,0 & 12,7 \\
\hline & $\mathrm{w}_{\text {depois }}(\%)$ & 12,8 & 13,1 & 13,4 & 12,9 \\
\hline & $\mathrm{e}$ & 0,40 & 0,42 & 0,42 & 0,43 \\
\hline & $\eta(\%)$ & 28 & 29 & 29 & 30 \\
\hline & $\mathrm{GC}(\%)$ & 97 & 98 & 98 & 99 \\
\hline \multirow{6}{*}{7 dias } & $\mathbf{C P}$ & 2.8 & 3.8 & 4.8 & 5.8 \\
\hline & $\mathrm{w}_{\text {antes }}(\%)$ & 9,5 & 12,7 & 11,4 & 12,4 \\
\hline & $\mathrm{w}_{\text {depois }}(\%)$ & 12,2 & 14,9 & 13,8 & 13,5 \\
\hline & e & 0,40 & 0,42 & 0,42 & 0,42 \\
\hline & $\eta(\%)$ & 28 & 29 & 29 & 30 \\
\hline & GC (\%) & 97 & 98 & 98 & 99 \\
\hline \multirow{6}{*}{28 dias } & $\mathbf{C P}$ & 2.9 & 3.9 & 4.9 & 5.9 \\
\hline & $\mathrm{w}_{\text {antes }}(\%)$ & 10,4 & 12,9 & 11,9 & 12,6 \\
\hline & $\mathrm{w}_{\text {depois }}(\%)$ & 13,1 & 14,4 & 15,4 & 13,7 \\
\hline & $\mathrm{e}$ & 0,40 & 0,41 & 0,45 & 0,42 \\
\hline & $\eta(\%)$ & 29 & 29 & 31 & 29 \\
\hline & $\mathrm{GC}(\%)$ & 97 & 98 & 96 & 99 \\
\hline
\end{tabular}

Obs.: $\mathrm{CP}=$ corpo de prova; $\mathrm{C}=$ Cascalho; $\mathrm{A}=$ areia; $\mathrm{CI}=$ cimento; $\mathrm{w}=$ umidade; $\mathrm{GC}=$ grau de compactação; $\mathrm{e}=$ índice de vazios; $\eta=$ porosidade.

Na Figura 5 está demonstrada a influência do aumento da umidade na resistência à compressão simples para as misturas com cascalho e cimento. Observa-se que para essas misturas, a cura úmida fez com que os corpos de prova ganhassem umidade com o aumento do período de cura. Isso pode ter impactado no comportamento das misturas com menor teor de cimento, fazendo com que a resistência não aumentasse. Por outro lado, verifica-se, ainda, que amostras com maiores teores de cimento apresentam maior resistência, devido à melhor interação entre os materiais. Conforme observado, existem três tendências de comportamento após o período de cura. Os corpos de prova sem cura permaneceram com a resistência constante, aproximadamente igual a 0,40 MPa para todos os teores. Já os corpos de prova com teores acima de $4 \%$ de cimento tiveram aumento de resistência aos 7 e 28 dias de cura, mesmo com o acréscimo de umidade. A exceção foi a mistura da obra $(\mathrm{C}+20 \% \mathrm{~A}+2 \% \mathrm{CI})$ que apresentou redução da resistência aos 28 dias, fato que pode estar relacionado com o ganho de umidade (aproximadamente 3,5\% em relação à umidade de moldagem) durante a cura. Já para as amostras com $2 \%$ de cimento, com o aumento da umidade a resistência permaneceu praticamente a mesma. 


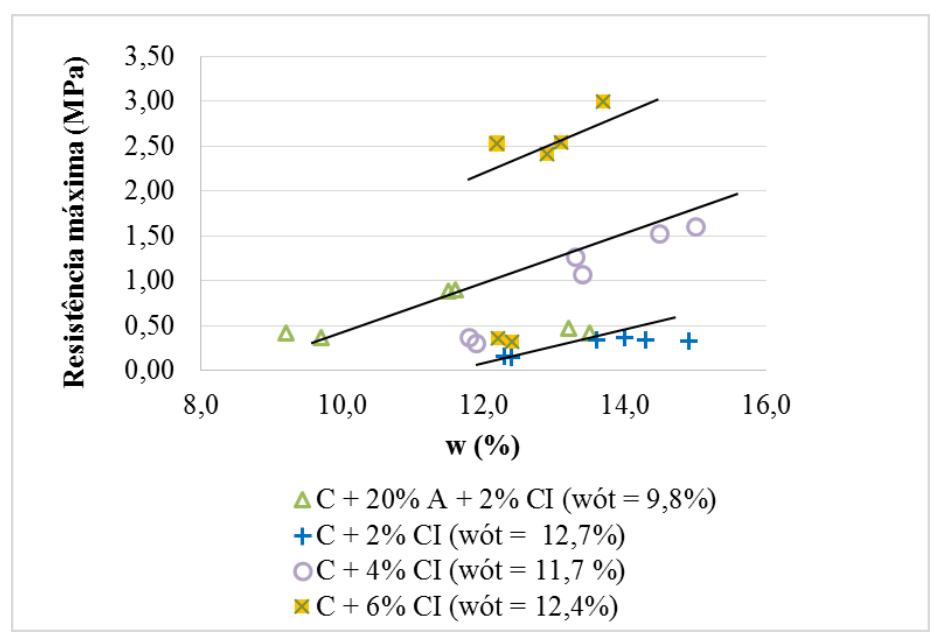

Figura 5: Relação entre resistência à compressão simples e a umidade após o período de cura.

Alguns estudos mostram que o acréscimo de resistência no concreto está associado com a relação entre quantidade de água livre e de cimento. Essa relação também pode ser importante de ser considerada nas pesquisas realizadas com solos estabilizados com cimento. No estudo feito com um solo laterítico da Tailândia e pedra britada estabilizados com cimento $(0,1,3,5$ e $7 \%)$ foi constatada a simetria da curva de compactação para os teores de umidade variando de 0,8 a 1,2 vezes o valor da umidade ótima. Nesse caso, teores de umidade menores que 0,6 vezes a umidade ótima foram insuficientes para a ocorrência do processo de hidratação. Os resultados laboratoriais e de microscopia mostraram que a resistência do solo estabilizado para uma energia de compactação específica $\left(293,3 \mathrm{~kJ} / \mathrm{m}^{3}\right)$ e teor de cimento $(5 \%)$ depende principalmente do teor de água [33]. Nos solos granulares estabilizados com cimento [33], verificaram-se a dependência entre a resistência à compressão simples e o fator água/cimento $(\mathrm{w} / \mathrm{C})$, sendo este um parâmetro relevante na análise do desenvolvimento da resistência de solos estabilizados para determinados tempos de cura. Os autores observaram que quanto mais baixo o parâmetro w/C, maior será a resistência, conforme já esperado, e que o papel da energia de compactação será de reduzir o teor de umidade ótima.

Outra questão que pode ser avaliada refere-se à porosidade, pois esta influencia diretamente no aumento ou na redução da resistência do solo-cimento. Quando a porosidade é menor, ocorre maior contato e intertravamento entre os grãos de solo, ocasionando um aumento da resistência. Quanto à relação água/cimento, a variação do teor de umidade para uma mesma porosidade pode modificar sua estrutura e, consequentemente, impactar no comportamento do material em termos de resistência [34].

Nesta pesquisa, independente do período de cura, tanto para os corpos de prova imersos com teor de $2 \%$ de cimento quanto para os não imersos antes da ruptura, a resistência permaneceu praticamente constante (Figura 4). Para o caso de menor teor de cimento (2\%), o aumento da saturação pode não ter desestabilizado a estrutura compactada, sendo que as ligações consolidadas não foram enfraquecidas pelo processo de imersão por quatro horas, ou esse tempo pode ter sido insuficiente para ocorrer mudanças bruscas. Já para as mistura com maior teor de cimento (4 e 6\%), observou-se maior queda nos valores da resistência quando são comparadas as situações sem e com imersão. Para rompimento imediato, na condição sem imersão, a resistência da mistura $\mathrm{C}+4 \% \mathrm{CI}$ permaneceu com o valor semelhante à condição com imersão. Para 7 dias de cura, com a imersão em água, a resistência reduziu 16\%, enquanto que para 28 dias a redução foi maior (37\%). Para a mistura C+ 6\%CI sem cura a RCS com imersão foi 14\% menor do que o valor da resistência do corpo de prova sem imersão. Para 7 e 28 dias de cura, essa redução foi de $27 \%$ e $30 \%$, respectivamente. As explicações para essas diferenças de comportamento podem estar relacionadas com a porosidade dos corpos de prova e a relação água/cimento conforme as referências apresentadas [33, 34].

JOEL e AGBEDE [35] ressaltam que o acréscimo adequado de teor de cimento Portland pode alterar drasticamente as propriedades das misturas. Os primeiros produtos que formam do contato do cimento com água são os silicatos de cálcio, aluminatos de cálcio hidratados e a cal hidratada. As partículas de cimento se unem umas às outras durante o endurecimento e formam um esqueleto rígido com as partículas de solo inalteradas. A cal hidratada formada é dissociada, produzindo base forte que dissolve a sílica e a alumina dos minerais argilosos. A partir da hidratação da sílica e da alumina, ocorre a reação com os íons de cálcio que estão livres; após a hidrólise do cimento são formados compostos insolúveis que endurecem com a cura para estabilizar o solo, sendo que esse processo é denominado de reações pozolânicas e é responsável pelo ganho 
de resistência ao longo do tempo. Neste estudo, observou-se que a incorporação dos teores de 4 e $6 \%$ de cimento ao solo ocasionou aumento de resistência provavelmente devido à formação de uma estrutura mais rígida para o período de cura maior.

Ao observar as umidades após o fim do período de cura nas Tabelas 6 e 7, constata-se que as misturas cascalho-cimento curadas em câmara úmida ganharam umidade de aproximadamente $2 \%$ para os períodos de cura de 7 e 28 dias, no procedimento de ensaio sem imersão. A exceção foi a amostra $\mathrm{C}+20 \% \mathrm{~A}+2 \% \mathrm{CI}$, cujo ganho de umidade foi de aproximadamente $3 \%$ para 28 dias. Segundo HORPIBULSUK et al. [33], quando o teor de água aumenta em um solo granular de baixa plasticidade compactado, a resistência e a rigidez diminuem, fato atribuído a redução da sucção matricial. A mistura $\mathrm{C}+6 \% \mathrm{CI}$ apresentou o menor ganho de umidade com a cura. Isso pode estar associado ao fato da estrutura estar mais densa e menos porosa, ou seja, pode ter ocorrido um melhor intertravamento dos produtos de hidratação com o solo, conforme será discutido nas imagens de microscopias.

Para as misturas de cascalho com cal, foi analisada somente a condição sem imersão, pois a norma ASTM D 5102 [23] não especifica o procedimento do ensaio com imersão. Os valores das resistências máximas obtidas estão apresentados na Figura 6. A umidade de moldagem, o grau de compactação, o índice de vazios e a porosidade de cada amostra de cascalho com cal ensaiada estão apresentados na Tabela 8 . Diferente do que aconteceu para algumas amostras das mistura do cascalho com cimento, não foram observadas variações significativas nas umidades após o período de cura. O índice de vazios dos corpos de prova variou entre 0,40 e 0,49 e o grau de compactação mínimo obtido foi de $95 \%$.

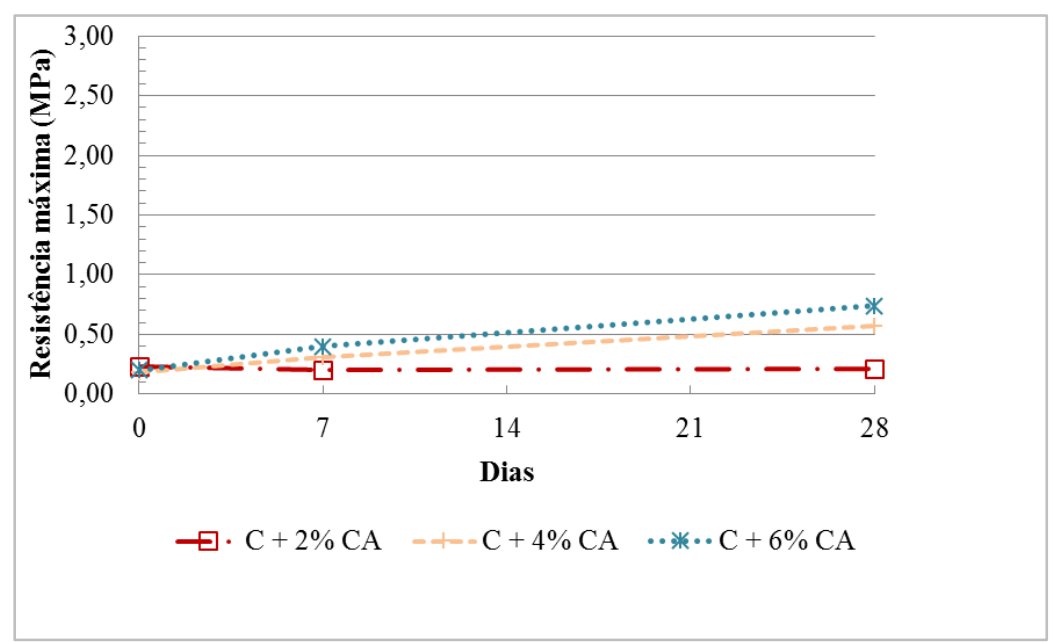

Figura 6: Valores de RCS obtidos para as amostras cascalho-cal.

Tabela 8: Dados de moldagem e umidade após os períodos de cura analisados das amostras de cascalho-cal.

\begin{tabular}{|c|c|c|c|c|c|c|c|}
\hline \multicolumn{2}{|c|}{ PARÂMETROS } & \multicolumn{2}{|c|}{$\mathrm{C}+2 \% \mathrm{CA}$} & \multicolumn{2}{|c|}{$\mathrm{C}+4 \% \mathrm{CA}$} & \multicolumn{2}{|c|}{$\mathrm{C}+6 \% \mathrm{CA}$} \\
\hline \multirow{6}{*}{ Sem cura } & CP & 6.1 & 6.2 & 7.1 & 7.2 & 8.1 & 8.2 \\
\hline & $\mathrm{w}_{\text {antes }}(\%)$ & 11,7 & 12,6 & 12,8 & 13,5 & 12,8 & 13,3 \\
\hline & $\mathrm{w}_{\text {depois }}(\%)$ & 11,3 & 11,5 & 12,8 & 12,9 & 12,9 & 13,1 \\
\hline & $\mathrm{e}$ & 0,49 & 0,45 & 0,49 & 0,43 & 0,40 & 0,44 \\
\hline & $\eta(\%)$ & 33 & 31 & 33 & 30 & 29 & 30 \\
\hline & $\mathrm{GC}(\%)$ & 95 & 97 & 97 & 101 & 104 & 101 \\
\hline \multirow{6}{*}{7 dias } & $\mathbf{C P}$ & 6.3 & 6.4 & 7.3 & 7.4 & 8.3 & 8.4 \\
\hline & $\mathrm{w}_{\text {antes }}(\%)$ & 11,8 & 11,8 & 12,3 & 13,6 & 12,9 & 13,0 \\
\hline & $\mathrm{w}_{\text {depois }}(\%)$ & 11,1 & 11,8 & 12,3 & 12,5 & 12,8 & 12,4 \\
\hline & $\mathrm{e}$ & 0,47 & 0,44 & 0,46 & 0,42 & 0,44 & 0,45 \\
\hline & $\eta(\%)$ & 32 & 30 & 32 & 29 & 30 & 31 \\
\hline & GC (\%) & 96 & 98 & 99 & 101 & 101 & 100 \\
\hline \multirow{6}{*}{28 dias } & CP & 6.5 & 6.6 & 7.5 & 7.6 & 8.5 & 8.6 \\
\hline & $\mathrm{w}_{\text {antes }}(\%)$ & 11,7 & 12,0 & 12,5 & 12,5 & 12,6 & 13,1 \\
\hline & $\mathrm{w}_{\text {depois }}(\%)$ & 11,3 & 11,2 & 11,5 & 12,0 & 12,4 & 12,7 \\
\hline & $\mathrm{e}$ & 0,48 & 0,46 & 0,47 & 0,46 & 0,44 & 0,46 \\
\hline & $\eta(\%)$ & 33 & 32 & 32 & 32 & 30 & 32 \\
\hline & GC (\%) & 95 & 95 & 98 & 98 & 101 & 100 \\
\hline
\end{tabular}

Obs.: $\mathrm{CP}=$ corpo de prova; $\mathrm{S}=$ Solo; $\mathrm{CA}=\mathrm{cal} ; \mathrm{w}=$ umidade; $\mathrm{GC}=$ grau de compactação; $\mathrm{e}=$ índice de vazios; $\eta=$ porosidade. 
Como pode ser observado, ao acrescentar cal ao cascalho laterítico obteve-se pequeno acréscimo na resistência. Para esse solo granular, o acréscimo de $2 \%$ de cal não alterou a resistência ao longo do tempo, o que indica que baixos teores de cal não são suficientes para reagirem com os minerais da fração mais fina do cascalho laterítico. Para os demais teores, verificou-se maior ganho de resistência ao longo dos 28 dias, porém os valores mínimos exigidos na norma não foram alcançados. Em alguns casos, a resistência de solos cauliníticos com o teor ótimo de cal não varia significativamente com o tempo de cura; já para os solos montmoriloníticos, a resistência geralmente aumenta com o tempo de cura, pois esses argilominerais expansivos possuem em sua composição uma quantidade maior de óxidos de ferro, magnésio e cálcio, além de ter uma capacidade de troca catiônica maior do que os argilominerais não expansivos, como a caulinita [7]. Neste estudo, o cascalho avaliado provavelmente não apresenta montmorilonita e, por esse motivo, a estabilização com cal hidratada não gerou ganhos de resistência significativos. Essa questão é melhor avaliada na apresentação dos resultados dos ensaios de difração de raios-X.

CONSOLI et al. [36] analisaram um solo siltoso tratado com diferentes teores de cal hidratada (3\%, $5 \%, 7 \%, 9 \%$ e $11 \%$ ) e observaram que quando ocorre redução na porosidade, há aumento na resistência do solo com cal, com o aumento do período de cura de 28 para 90 dias, como esperado. Esse fato estaria associado com a existência de um grande número de contatos na mistura compactada e maior tempo de cura, podendo o parâmetro de porosidade ser considerado nas análises. Porém, neste estudo não foi verificada a existência de uma relação direta entre a porosidade e a resistência para o cascalho estabilizado com cal.

\subsection{Triaxial Dinâmico}

Os ensaios para determinação do módulo de resiliência foram realizados com o intuito de obter resultados mecânicos consistentes, já que os dados preliminares apresentados no projeto da rodovia foram baseados apenas no parâmetro ISC, que mostra-se equivocado e ineficiente para aplicação de misturas estabilizadas em pavimentação. Inicialmente, realizou-se os ensaios com as mesmas dosagens utilizadas para os ensaios de compressão simples, com a moldagem de dois corpos de prova para cada tempo de cura ( 0,7 e 28 dias). Porém, devido ao atraso na instalação do equipamento UTM-30, o período de cura de 28 dias estendeu para um intervalo maior, variando entre 50 e 56 dias. Na Tabela 9 e na Tabela 10, estão apresentados os parâmetros obtidos durante a moldagem dos corpos de prova e a umidade após a realização dos ensaios. Para as misturas com cimento, os valores de umidade variaram entre 9,1 e 14,6\%, de índice de vazios variaram entre 0,40 e 0,47 e o grau de compactação mínimo foi de $95 \%$ (Tabela 9). Os valores de umidade obtidos depois do ensaio foram maiores pelo fato de ter sido realizada a cura úmida dos corpos de prova ensaiados. Para as misturas com cal, os valores de umidade variaram entre 11,1 e $13,2 \%$, de índice de vazios variaram entre $0,42 \mathrm{e}$ 0,51 e o grau de compactação mínimo foi de $95 \%$ (Tabela 10).

Durante os ensaios foram obtidos resultados dos módulos de resiliência após a aplicação da sequência de 18 pares de tensões para cada amostra ensaiada conforme a norma ME 134 [27]. Os resultados obtidos para as diversas misturas estudadas foram analisados de diferentes maneiras, de acordo com os modelos existentes na literatura para verificar qual representa melhor o comportamento dos módulos de resiliência (MR) em relação ao estado de tensões: MR em função da tensão confinante $\left(\sigma_{3}\right)$, MR em função da tensão desvio $\left(\sigma_{\mathrm{d}}\right)$, MR em função da $\sigma_{3}$ e $\sigma_{\mathrm{d}}$ (modelo composto) e o modelo universal, que relaciona a pressão atmosférica $\left(\mathrm{P}_{\mathrm{a}}\right)$, tensão cisalhante octaédrica $\left(\tau_{\text {oct }}\right)$ e primeiro invariante de tensões $(\theta)$.

Após a realização dos ensaios, verificou-se que os resultados obtidos para os corpos de prova 2.5, 4.1, 4.4, 5.2 constituídos de cascalho com cimento e 6.3 composto de cascalho com cal foram inconsistentes (apresentaram valores elevados de módulo de resiliência, ocasionando uma dispersão maior dos dados obtidos) e, portanto, foram desconsiderados das análises. Para os demais ensaios, foram realizadas regressões multilineares dos dados para verificação de quais modelos melhor representavam o comportamento de cada material. Da Tabela 11 a Tabela 13 são apresentadas as equações obtidas a partir dos valores médios de módulos determinados nos ensaios para amostras sem cura, com 7 e entre 50 a 56 dias de cura, respectivamente. Os modelos que melhor representaram a relação do MR com as tensões para os materiais estudados foram o modelo composto e universal.

Ressalta-se que alguns valores obtidos de módulo de resiliência durante o ensaio para as amostras de cascalho-cimento foram elevados para determinados pares de tensão aplicados. Isso ocasionou valores elevados para a constante experimental $\left(\mathrm{k}_{1}\right)$ para as amostras com 4 e $6 \%$ de cimento com 7 e 50 dias de cura. Esse fato não ocorreu com as amostras de cal. Essas diferenças de comportamento podem estar relacionadas com questões microestruturais conforme discutido a seguir. 
Tabela 9: Dados de moldagem e umidade após os períodos de cura dos corpos de prova de cascalho natural e cascalhocimento para os ensaios triaxiais dinâmico.

\begin{tabular}{|c|c|c|c|c|c|c|c|c|c|c|c|}
\hline \multicolumn{2}{|c|}{ PARÂMETROS } & \multicolumn{2}{|c|}{ CASCALHO } & \multicolumn{2}{|c|}{$\mathrm{C}+20 \% \mathrm{~A}+2 \% \mathrm{Cl}$} & \multicolumn{2}{|c|}{$\mathrm{C}+2 \% \mathrm{Cl}$} & \multicolumn{2}{|c|}{$\mathrm{C}+4 \% \mathrm{Cl}$} & \multicolumn{2}{|c|}{$\mathrm{C}+6 \% \mathrm{Cl}$} \\
\hline \multirow{5}{*}{ Sem cura } & CP & 1.1 & 1.2 & 2.1 & 2.2 & 3.1 & 3.2 & 4.1 & 4.2 & 5.1 & 5.2 \\
\hline & $\mathrm{w}_{\text {antes }}(\%)$ & 10,7 & 10,8 & 9,3 & 9,1 & 12,6 & 11,9 & 11,6 & 12,0 & 11,9 & 12,1 \\
\hline & $\mathrm{e}$ & 0,42 & 0,43 & 0,40 & 0,40 & 0,43 & 0,44 & 0,42 & 0,42 & 0,40 & 0,41 \\
\hline & $\eta(\%)$ & 30 & 30 & 28 & 28 & 30 & 30 & 29 & 29 & 29 & 29 \\
\hline & $\mathrm{GC}(\%)$ & 96 & 96 & 97 & 97 & 97 & 97 & 98 & 98 & 101 & 100 \\
\hline \multirow{6}{*}{7 dias } & $\mathrm{CP}$ & - & - & 2.3 & 2.4 & 3.3 & 3.4 & 4.3 & 4.4 & 5.3 & 5.4 \\
\hline & $\mathrm{W}_{\text {antes }}(\%)$ & - & - & 9,5 & 9,3 & 11,9 & 11,8 & 12,0 & 12,2 & 11,6 & 12,6 \\
\hline & $\mathrm{w}_{\text {depois }}(\%)$ & - & - & 12,3 & 12,2 & 13,4 & 14,3 & 13,4 & 13,3 & 13,3 & 13,2 \\
\hline & $\mathrm{e}$ & - & - & 0,42 & 0,42 & 0,47 & 0,44 & 0,43 & 0,46 & 0,42 & 0,44 \\
\hline & $\eta(\%)$ & - & - & 30 & 30 & 32 & 30 & 30 & 32 & 30 & 30 \\
\hline & $\mathrm{GC}(\%)$ & - & - & 95 & 95 & 95 & 97 & 97 & 95 & 99 & 98 \\
\hline \multirow{6}{*}{$\begin{array}{l}50-56 \\
\text { dias }\end{array}$} & $\mathbf{C P}$ & - & - & 2.5 & 2.6 & 3.5 & 3.6 & 4.5 & 4.6 & 5.5 & 5.6 \\
\hline & $\mathrm{W}_{\text {antes }}(\%)$ & - & - & 9,5 & 9,8 & 12,3 & 12,6 & 11,8 & 11,4 & 11,9 & 12,5 \\
\hline & $\mathrm{w}_{\text {depois }}(\%)$ & - & - & 12,2 & 12,9 & 14,6 & 13,9 & 13,5 & 13,6 & 13,0 & 13,6 \\
\hline & $\mathrm{e}$ & - & - & 0,40 & 0,43 & 0,43 & 0,42 & 0,46 & 0,45 & 0,43 & 0,45 \\
\hline & $\eta(\%)$ & - & - & 29 & 30 & 30 & 29 & 32 & 31 & 30 & 31 \\
\hline & GC (\%) & - & - & 97 & 95 & 97 & 98 & 95 & 96 & 98 & 98 \\
\hline
\end{tabular}

Obs.: $\mathrm{CP}=$ corpo de prova; $\mathrm{C}=$ Cascalho; $\mathrm{A}=$ areia; $\mathrm{CI}=$ cimento; $\mathrm{w}=$ umidade; $\mathrm{GC}=$ grau de compactação; $\mathrm{e}=$ índice de vazios; $\eta=$ porosidade.

Tabela 10: Dados de moldagem e umidade após os períodos de cura dos corpos de prova de cascalho-cal para os ensaios triaxiais dinâmicos.

\begin{tabular}{|c|c|c|c|c|c|c|c|}
\hline \multicolumn{2}{|c|}{ PARÂMETROS } & \multicolumn{2}{|c|}{$\mathrm{C}+2 \% \mathrm{CA}$} & \multicolumn{2}{|c|}{$\mathrm{C}+4 \% \mathrm{CA}$} & \multicolumn{2}{|c|}{$\mathrm{C}+6 \% \mathrm{CA}$} \\
\hline \multirow{5}{*}{ Sem cura } & $\mathbf{C P}$ & 6.1 & 6.2 & 7.1 & 7.2 & 8.1 & 8.2 \\
\hline & $\mathrm{W}_{\text {antes }}(\%)$ & 12,2 & 11,1 & 12,4 & 12,1 & 12,1 & 12,2 \\
\hline & $\mathrm{e}$ & 0,48 & 0,47 & 0,45 & 0,46 & 0,46 & 0,47 \\
\hline & $\eta(\%)$ & 33 & 32 & 31 & 32 & 32 & 32 \\
\hline & GC (\%) & 95 & 96 & 100 & 99 & 100 & 99 \\
\hline \multirow{6}{*}{7 dias } & $\mathbf{C P}$ & 6.3 & 6.4 & 7.3 & 7.4 & 8.3 & 8.4 \\
\hline & $\mathrm{W}_{\text {antes }}(\%)$ & 12,2 & 12,2 & 12,4 & 12,5 & 12,0 & 12,5 \\
\hline & $\mathrm{w}_{\text {depois }}(\%)$ & 12,5 & 11,9 & 12,4 & 12,3 & 12,0 & 12,3 \\
\hline & $\mathrm{e}$ & 0,49 & 0,48 & 0,46 & 0,45 & 0,42 & 0,48 \\
\hline & $\eta(\%)$ & 33 & 33 & 32 & 31 & 29 & 33 \\
\hline & GC (\%) & 95 & 96 & 100 & 99 & 100 & 99 \\
\hline \multirow{6}{*}{ 50-56 dias } & $\mathbf{C P}$ & 6.5 & 6.6 & 7.5 & 7.6 & 8.5 & 8.6 \\
\hline & $\mathrm{W}_{\text {antes }}(\%)$ & 11,7 & 11,9 & 12,0 & 13,2 & 12,7 & 12,8 \\
\hline & $\mathrm{w}_{\text {depois }}(\%)$ & 10,6 & 11,0 & 11,3 & 12,3 & 11,5 & 12,6 \\
\hline & $\mathrm{e}$ & 0,50 & 0,48 & 0,46 & 0,45 & 0,51 & 0,48 \\
\hline & $\eta(\%)$ & 33 & 33 & 32 & 31 & 34 & 33 \\
\hline & GC (\%) & 95 & 96 & 100 & 99 & 100 & 99 \\
\hline
\end{tabular}

Obs.: $\mathrm{CP}=$ corpo de prova; $\mathrm{C}=$ Cascalho; $\mathrm{A}=$ areia; $\mathrm{CA}=$ cal; $\mathrm{w}=$ umidade; $\mathrm{GC}=$ grau de compactação; $\mathrm{e}=$ índice de vazios; $\eta=$ porosidade.

Tabela 11: Modelos obtidos para as amostras estudadas sem cura

\begin{tabular}{l|c|l}
\hline AMOSTRAS (SEM CURA) & EQUAÇÃO & $\mathbf{R}^{\mathbf{2}}$ \\
\hline Cascalho natural & $\mathrm{MR}=3387,88 \sigma_{3}{ }^{0,516} \sigma_{\mathrm{d}}{ }^{0,172}$ & 0,99 \\
\hline $\mathrm{C}+20 \% \mathrm{~A}+2 \% \mathrm{CI}$ & $\mathrm{MR}=2368,00 \sigma_{3}{ }^{0,345} \sigma_{\mathrm{d}}{ }^{0,039}$ & 0,92 \\
\hline $\mathrm{C}+2 \% \mathrm{CI}$ & $\mathrm{MR}=3664,15 \sigma_{3}{ }^{0,670} \sigma_{\mathrm{d}}{ }^{-0,065}$ & 0,90 \\
\hline $\mathrm{C}+4 \% \mathrm{CI}$ & $\mathrm{MR}=1855,93 \mathrm{P}_{\mathrm{a}}\left(\frac{\theta}{\mathrm{P}_{\mathrm{a}}}\right)^{0,851}\left(\frac{\tau_{\mathrm{oct}}}{\mathrm{P}_{\mathrm{a}}}+1\right)^{-1,216}$ & 0,92 \\
\hline $\mathrm{C}+6 \% \mathrm{CI}$ & $\mathrm{MR}=5488,52 \sigma_{3}{ }^{0,985} \sigma_{\mathrm{d}}{ }^{-0,440}$ & 0,72 \\
\hline $\mathrm{C}+2 \% \mathrm{CA}$ & $\mathrm{MR}=3140,07 \sigma_{3}{ }^{0,565} \sigma_{\mathrm{d}}{ }^{-0,086}$ & 0,86 \\
\hline $\mathrm{C}+4 \% \mathrm{CA}$ & $\mathrm{MR}=4411,79 \sigma_{3}{ }^{0,667} \sigma_{\mathrm{d}}{ }^{0,072}$ & 0,96 \\
\hline $\mathrm{C}+6 \% \mathrm{CA}$ & $\mathrm{MR}=2955,83 \sigma_{3}{ }^{0,461} \sigma_{\mathrm{d}}{ }^{0,124}$ & 0,98 \\
\hline
\end{tabular}

Obs.: $\mathrm{MR}=$ módulo de resiliência; $\mathrm{C}=$ Cascalho; $\mathrm{A}=$ areia; $\mathrm{CI}=$ cimento; $\sigma_{3}=$ tensão confinante; $\sigma_{\mathrm{d}}=$ tensão desvio; $\mathrm{P}_{\mathrm{a}}=$ pressão atmosférica; $\theta=$ primeiro invariante de tensões; $\tau_{\text {oct }}=$ tensão cisalhante octaédrica; $\mathrm{R}^{2}=$ coeficiente de determinação. 
Tabela 12: Modelos obtidos para as amostras estudadas com 7 dias de cura

\begin{tabular}{l|l|l}
\hline AMOSTRAS (SEM CURA) & EQUAÇÃO & $\mathbf{R}^{\mathbf{2}}$ \\
\hline $\mathrm{C}+20 \% \mathrm{~A}+2 \% \mathrm{CI}$ & $\mathrm{MR}=6335,70 \mathrm{P}_{\mathrm{a}}\left(\frac{\theta}{\mathrm{P}_{\mathrm{a}}}\right)^{-0,004}\left(\frac{\tau_{\mathrm{oct}}}{\mathrm{P}_{\mathrm{a}}}+1\right)^{0,931}$ & 0,88 \\
\hline $\mathrm{C}+2 \% \mathrm{CI}$ & $\mathrm{MR}=3663,36 \mathrm{P}_{\mathrm{a}}\left(\frac{\theta}{\mathrm{P}_{\mathrm{a}}}\right)^{-0,040}\left(\frac{\tau_{\mathrm{oct}}}{\mathrm{P}_{\mathrm{a}}}+1\right)^{0,952}$ & 0,86 \\
\hline $\mathrm{C}+4 \% \mathrm{CI}$ & $\mathrm{MR}=37840,88 \mathrm{P}_{\mathrm{a}}\left(\frac{\theta}{\mathrm{P}_{\mathrm{a}}}\right)^{0,727}\left(\frac{\tau_{\mathrm{oct}}}{\mathrm{P}_{\mathrm{a}}}+1\right)^{-0,457}$ & 0,62 \\
\hline $\mathrm{C}+6 \% \mathrm{CI}$ & $\mathrm{MR}=32429,13 \mathrm{P}_{\mathrm{a}}\left(\frac{\theta}{\mathrm{P}_{\mathrm{a}}}\right)^{0,786}\left(\frac{\tau_{\mathrm{oct}}}{\mathrm{P}_{\mathrm{a}}}+1\right)^{-0,052}$ & 0,61 \\
\hline $\mathrm{C}+2 \% \mathrm{CA}$ & $\mathrm{MR}=2437,00 \sigma_{3}{ }^{0,463} \sigma_{\mathrm{d}}{ }^{-0,147}$ & 0,74 \\
\hline $\mathrm{C}+4 \% \mathrm{CA}$ & $\mathrm{MR}=3069,65 \sigma_{3}{ }^{0,465} \sigma_{\mathrm{d}}{ }^{0,108}$ & 0,96 \\
\hline $\mathrm{C}+6 \% \mathrm{CA}$ & $\mathrm{MR}=2393,48 \sigma_{3}{ }^{0,302} \sigma_{\mathrm{d}}{ }^{0,042}$ & 0,84 \\
\hline $\begin{array}{l}\text { Obs.: MR }=\text { módulo de resiliência; } \mathrm{C}=\text { Cascalho; } \mathrm{A}=\text { areia; } \mathrm{CI}=\text { cimento; } \sigma_{3}=\text { tensão confinante; } \sigma_{\mathrm{d}}=\text { tensão desvio; } \mathrm{P}_{\mathrm{a}}= \\
\text { pressão atmosférica; } \theta=\text { primeiro invariante de tensões; } \tau_{\text {oct }}=\text { tensão cisalhante octaédrica; } \mathrm{R}^{2}=\text { coeficiente de determinação. }\end{array}$
\end{tabular}

Tabela 13: Modelos obtidos para as amostras estudadas com 50-56 dias de cura

\begin{tabular}{l|c|l}
\hline AMOSTRAS (SEM CURA) & EQUAÇÃO & $\mathbf{R}^{2}$ \\
\hline $\mathrm{C}+20 \% \mathrm{~A}+2 \% \mathrm{CI}$ & $\mathrm{MR}=7947,46 \mathrm{P}_{\mathrm{a}}\left(\frac{\theta}{\mathrm{P}_{\mathrm{a}}}\right)^{0,254}\left(\frac{\tau_{\mathrm{oct}}}{\mathrm{P}_{\mathrm{a}}}+1\right)^{0,541}$ & 0,91 \\
\hline $\mathrm{C}+2 \% \mathrm{CI}$ & $\mathrm{MR}=4527,52 \sigma_{3}^{0,733} \sigma_{\mathrm{d}}{ }^{-0,430}$ & 0,68 \\
\hline $\mathrm{C}+4 \% \mathrm{CI}$ & $\mathrm{MR}=41981,62 \mathrm{P}_{\mathrm{a}}\left(\frac{\theta}{\mathrm{P}_{\mathrm{a}}}\right)^{0,229}\left(\frac{\tau_{\mathrm{oct}}}{\mathrm{P}_{\mathrm{a}}}+1\right)^{0,585}$ & 0,78 \\
\hline $\mathrm{C}+6 \% \mathrm{CI}$ & $\mathrm{MR}=2585,36 \sigma_{3}^{0,373} \sigma_{\mathrm{d}}^{0,070}$ & 0,93 \\
\hline $\mathrm{C}+4 \% \mathrm{CA}$ & $\mathrm{MR}=4208,33 \mathrm{P}_{\mathrm{a}}\left(\frac{\theta}{\mathrm{P}_{\mathrm{a}}}\right)^{0,290}\left(\frac{\tau_{\mathrm{oct}}}{\mathrm{P}_{\mathrm{a}}}+1\right)^{0,712}$ & 0,96 \\
\hline $\mathrm{C}+6 \% \mathrm{CA}$ & $\mathrm{MR}=5261,44 \mathrm{P}_{\mathrm{a}}\left(\frac{\theta}{\mathrm{P}_{\mathrm{a}}}\right)^{-0,001}\left(\frac{\tau_{\mathrm{oct}}}{\mathrm{P}_{\mathrm{a}}}+1\right)^{0,927}$ & 0,83 \\
\hline
\end{tabular}

Obs.: $\mathrm{MR}=$ módulo de resiliência; $\mathrm{C}=$ Cascalho; $\mathrm{A}=$ areia; $\mathrm{CI}=$ cimento; $\sigma_{3}=$ tensão confinante; $\sigma_{\mathrm{d}}=$ tensão desvio; $\mathrm{P}_{\mathrm{a}}=$ pressão atmosférica. $\theta=$ primeiro invariante de tensões; $\tau_{\text {oct }}=$ tensão cisalhante octaédrica; $\mathrm{R}^{2}=$ coeficiente de determinação.

A partir dos resultados obtidos nas análises, foi possível avaliar se os valores de módulos de resiliência encontrados estão adequados para a camada de base da rodovia GO-080. Para tanto, foram obtidas as tensões confinantes, desvio e cisalhante octaédrica atuantes no meio dessa camada por meio de um método analítico. Também foram obtidos os valores de deflexão elástica no topo da camada de revestimento do ponto localizado abaixo do carregamento de eixo padrão rodoviário e a deformação vertical no topo do subleito. Para essa análise, utilizou-se o programa KENLAYER [37], optando-se pela realização de análises elásticolineares. Para tanto, foram definidos alguns parâmetros de entrada da estrutura do pavimento correspondente ao projeto, como:

- $\quad$ Carga atuante de pneu com $11 \mathrm{~cm}$ de diâmetro e pressão de contato correspondente a 0,56 MPa (eixo padrão rodoviário);

- $\quad$ Revestimento do tipo concreto betuminoso usinado a quente (CBUQ) com $5 \mathrm{~cm}$ de espessura, com MR igual a $2000 \mathrm{MPa}$ e coeficiente de Poisson (v) igual a 0,33;

- $\quad$ Base de $20 \mathrm{~cm}$ de espessura, com MR obtido conforme a equação do modelo analisado e $v$ adotado igual a 0,35 ;

- $\quad$ Sub-base com $20 \mathrm{~cm}$ de espessura, MR igual a $300 \mathrm{MPa}$ e $v$ igual a 0,40 ;

- $\quad$ Subleito considerado com espessura semi-infinita, com MR igual a $100 \mathrm{MPa}$ e v igual a 0,45.

Observou-se que para as amostras com 4 e $6 \%$ de cimento analisadas com 7 e aproximadamente 50 dias de cura, o modelo composto apresentou o melhor $\mathrm{R}^{2}$. No entanto, nessas análises foram obtidas tensões confinantes $\left(\sigma_{3}\right)$ negativas, o que representa no software KENLAYER tensões de tração, inviabilizando o cálculo do módulo de resiliência. Nesses casos, adotou-se o modelo universal que considera o primeiro invariante de tensões $(\theta)$ e a tensão cisalhante octaédrica $\left(\tau_{\text {oct }}\right)$. Os resultados obtidos mostraram que os módulos foram elevados para as misturas com teores maiores que 4\% de cimento em relação ao módulo de resiliência adotado para a camada do revestimento, indicando que nessas situações a camada de base apresenta compor- 
tamento semi-rígido. Resultados semelhantes foram obtidos para misturas estabilizadas com teores acima de 4\% de cimento por POTTURI [38]. KHALI HANIFA et al. [39] também consideraram os modelos constitutivos em função das variáveis $\theta$ e $\tau_{\text {oct }}$ para determinar os módulos de resiliência de materiais inconsolidados estabilizados com teores superiores a $6 \%$ para a camada de base.

Em seguida, foram calculados os valores dos números de eixo padrão $\left(\mathrm{N}_{\mathrm{D}}\right.$ e $\left.\mathrm{N}_{\text {sub }}\right)$ correspondentes às deflexões elásticas do topo do revestimento e à deformação vertical do topo do subleito, respectivamente. Para tanto, foram utilizados os modelos apresentados no procedimento PRO 11/79 [40], e por DORMON e METCALF[41] recomendados pelo Departamento de Estradas e Rodagem de São Paulo (DER-SP) [42]. Da Figura 7 a 9 estão mostrados os resultados obtidos da análise do comportamento mecanístico de cada mistura estudada.

Dos resultados obtidos, nota-se que as estruturas avaliadas apresentaram deflexões elásticas no topo revestimento inferiores a $61.10^{-2} \mathrm{~mm}$, independente do período de cura (Figura7a, Figura8a e Figura9a), sendo que essa situação é considerada satisfatória para um pavimento novo. Já em relação à deformação no topo do subleito para a condição sem cura (Figura 7b), os valores permaneceram próximos, mas pode-se observar o menor valor de deformação para a amostra $\mathrm{C}+20 \% \mathrm{~A}+2 \% \mathrm{CI}$, onde o valor obtido para esse parâmetro foi de $4,05 \times 10^{-4}$ ). Ao analisar esse parâmetro em função dos tempos de cura (Figura 8b e 9b), observa-se que as misturas com $4 \%$ e $6 \%$ de cimento apresentaram melhor desempenho.

Em termos de $\mathrm{N}_{D}$ e $\mathrm{N}_{S U B}$, sem considerar o período de cura (Figura 7c), verifica-se que a mistura do cascalho com $20 \%$ de areia mais $2 \%$ de cimento teria capacidade de suportar maior tráfego e o cascalho natural e as misturas com 2 e $6 \%$ de cal apresentaram comportamento semelhantes. No entanto, ao avaliar esses parâmetros em função do tempo (Figura 8c e 9c), novamente observa-se o melhor desempenho para as misturas com $4 \%$ e $6 \%$ de cimento.
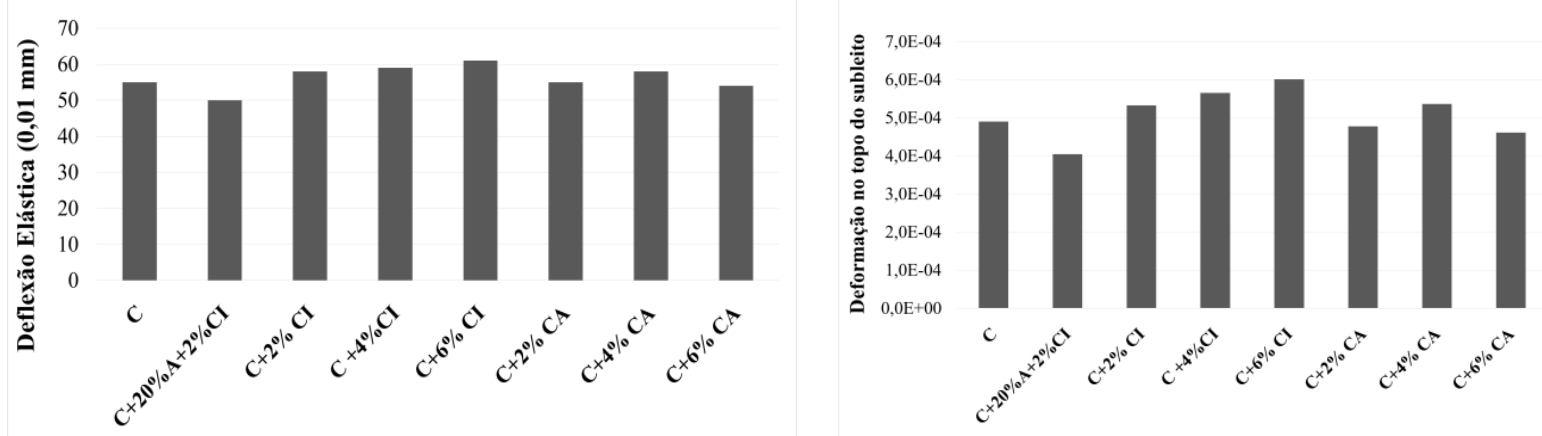

(a)

(b)
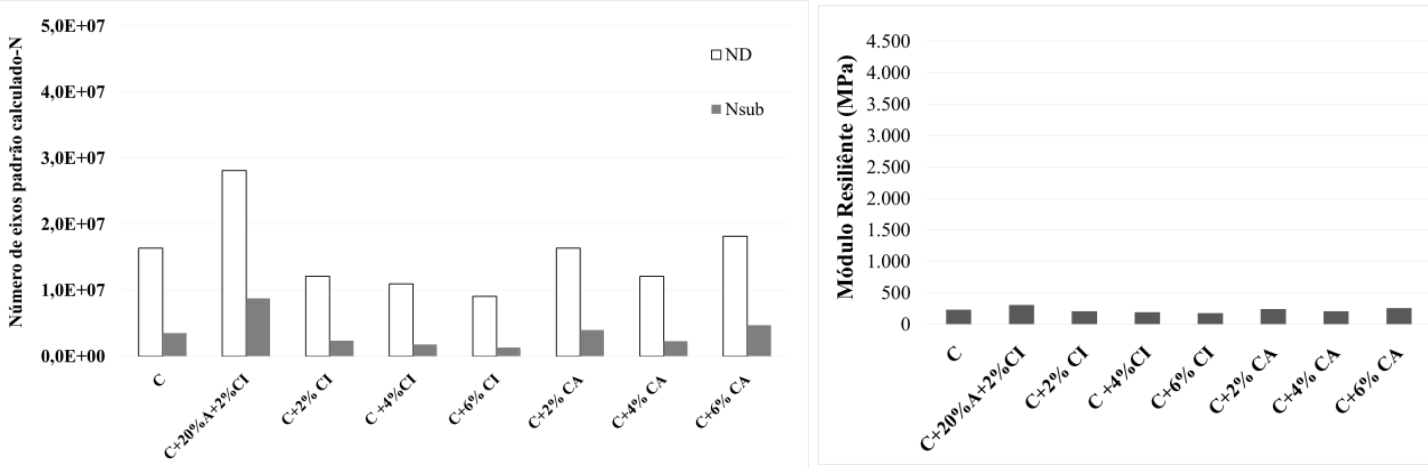

(c)

(d)

Figura 7: Parâmetros analisados das amostras sem cura: (a) Deflexão elástica no topo do revestimento; (b) Deformação vertical no topo do subleito para o solo; (c) Números de eixos padrão $\left(\mathrm{N}_{\mathrm{D}}\right.$ e $\left.\mathrm{N}_{\mathrm{SUB}}\right)$ (d) Módulos de resiliência. 


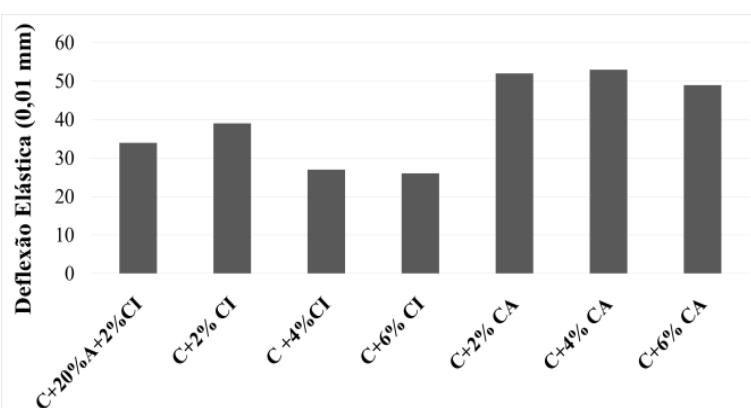

(a)

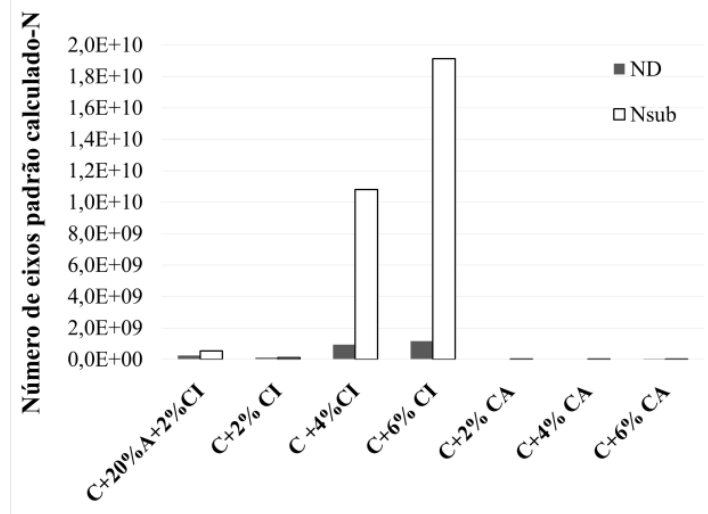

(c)

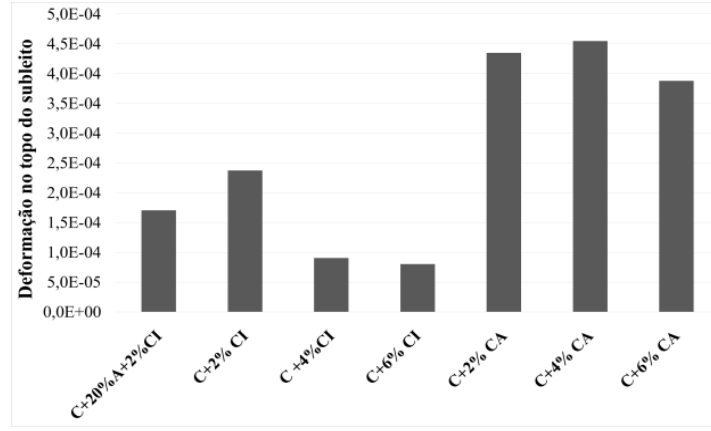

(b)

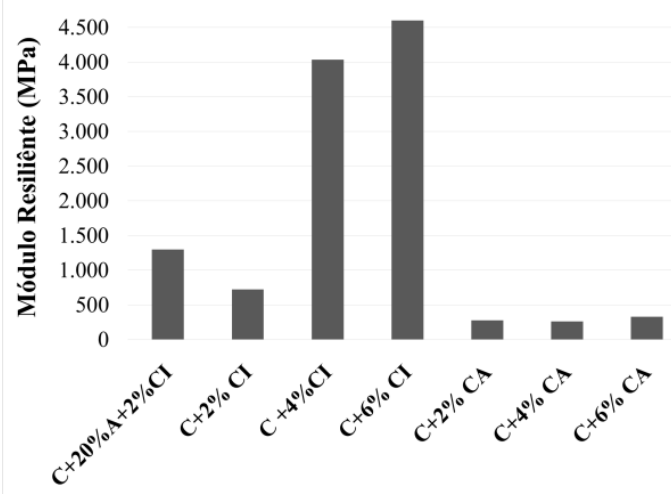

(d)

Figura 8: Parâmetros analisados das amostras 7 dias de cura: (a) Deflexão elástica no topo do revestimento; (b) Deformação vertical no topo do subleito para o solo; (c) Números de eixos padrão $\left(\mathrm{N}_{\mathrm{D}}\right.$ e $\left.\mathrm{N}_{\mathrm{SUB}}\right)$; (d) Módulos de resiliência.

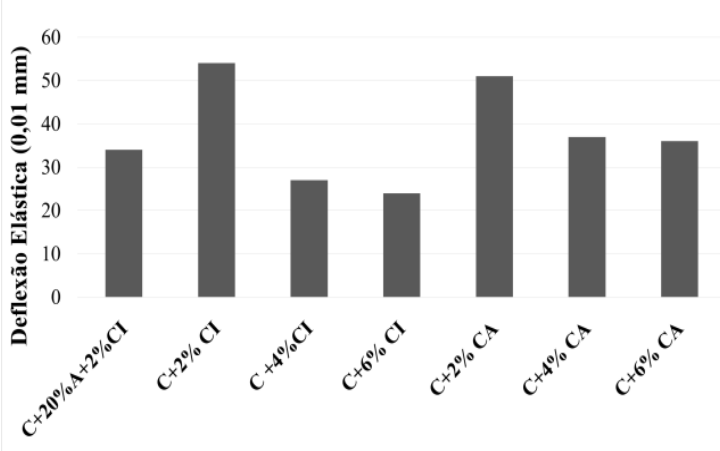

(a)

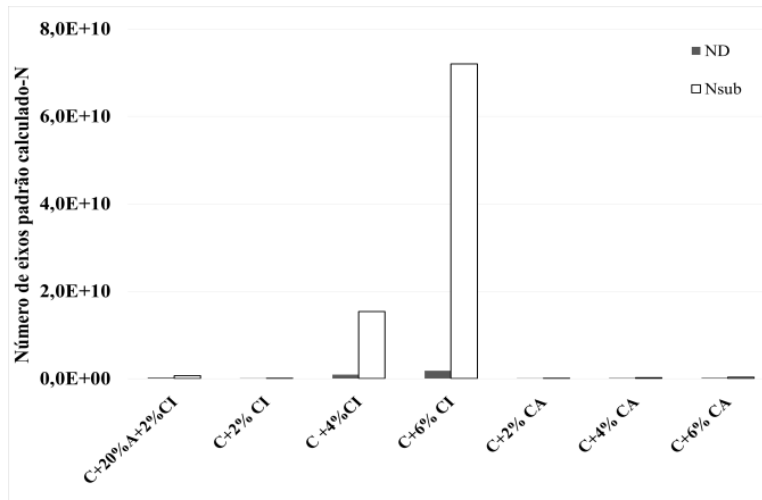

(c)

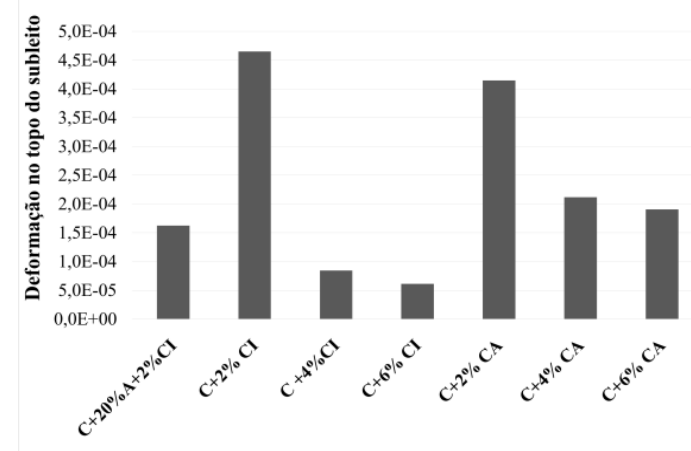

(b)

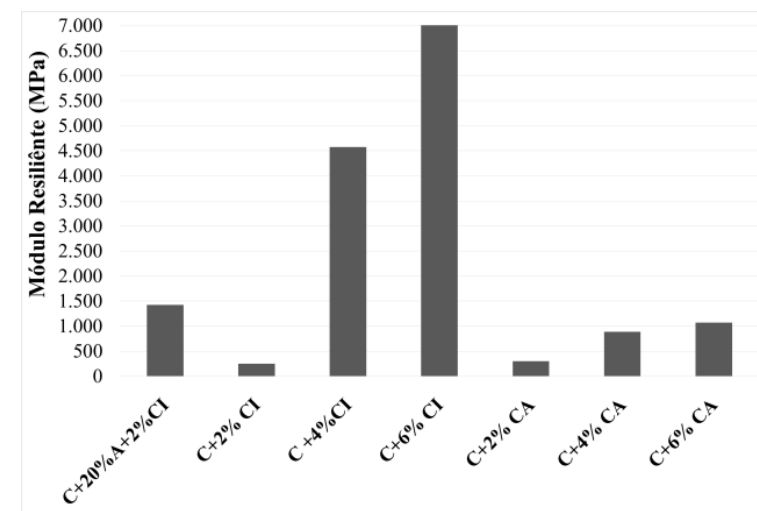

(d)

Figura 9: Parâmetros analisados das amostras com 50-56 dias de cura: (a) Deflexão elástica no topo do revestimento; (b) Deformação vertical no topo do subleito; (c) Números de eixos padrão $\left(\mathrm{N}_{\mathrm{D}}\right.$ e $\mathrm{N}_{\mathrm{SUB}}$ ); (d) Módulos de resiliência. 
Avaliando os valores de módulo de resiliência para os materiais de base estudados (Figura 7d, Figura 8d e Figura 9d), observa-se que, no geral, foram obtidos valores superiores a $180 \mathrm{MPa}$. Esse valor estaria na faixa de valores de módulo de resiliência da laterita sem estabilização, que pode variar entre 100 a $500 \mathrm{MPa}$, segundo BERNUCCI et al. [43] para ser empregada no projeto de uma rodovia. A mistura escolhida no projeto da GO-080 (C+20\%A + 2\% CI) apresentou valores elevados de módulo (acima de $300 \mathrm{MPa})$ e, nessa condição, é considerada adequada. No entanto, as misturas com maiores teores de cimento apresentaram valores de MR superior a $4000 \mathrm{MPa}$ em função do período de cura, fato que demonstra maior capacidade estrutural das mesmas. As misturas com cal apresentaram ligeiro aumento nos valor de MR, mas em comparação com as demais misturas, não se destacaram tanto. No caso da cal, sua influência pode ser mais significativa na capacidade de deformação.

Ao analisar os resultados dos ensaios triaxiais dinâmicos sob a ótica da teoria da elasticidade com o KENLAYER, é possível observar que foi obtido valor inesperado para a mistura $\mathrm{C}+2 \% \mathrm{CI}$ (por exemplo: $251 \mathrm{MPa}$ para a mistura com 51 dias de cura, ou seja, valor próximo da mistura sem cura) e que, nessa situação, não foi possível obter a tendência esperada do aumento do valor de MR em função do tempo de cura. Esse comportamento pode estar vinculado às condições de compactação dos corpos de prova e ao ganho de umidade na câmara úmida após o período de cura ou, ainda, a problemas na realização dos ensaios. Isso mostra a necessidade de maior controle na confecção dos corpos de prova para misturas estabilizadas quimicamente e da execução de maior número de ensaios triaxiais dinâmicos para o mesmo tipo de mistura. Assim, é possível verificar a influência do aumento da umidade com a cura úmida, principalmente para as misturas com baixo teor de cimento.

Por fim, constata-se que as misturas com $4 \%$ e $6 \%$ de cimento são as mais adequadas e absorvem melhor os esforços verticais produzidos pelo carregamento, protegendo mais o subleito. Esses teores apresentaram melhor desempenho também nos ensaios de compressão simples. As misturas com acréscimo de cal tiveram melhor desempenho do que em relação ao cascalho sem estabilização, porém foram obtidos valores menores de MR em relação às estabilizações com cimento, reafirmando a necessidade de existir uma maior quantidade de argila para serem obtidas melhores reações com a cal.

\subsection{Análise Mineralógica e Microestrutural}

$\mathrm{O}$ ensaio de difração de raios-X realizado com amostra de cascalho natural mostrou a presença dos minerais principais caulinita e goethita e como minerais subordinados estão a hematita e o quartzo (Figura 10). A presença desses minerais confirma que o cascalho estudado é laterítico.

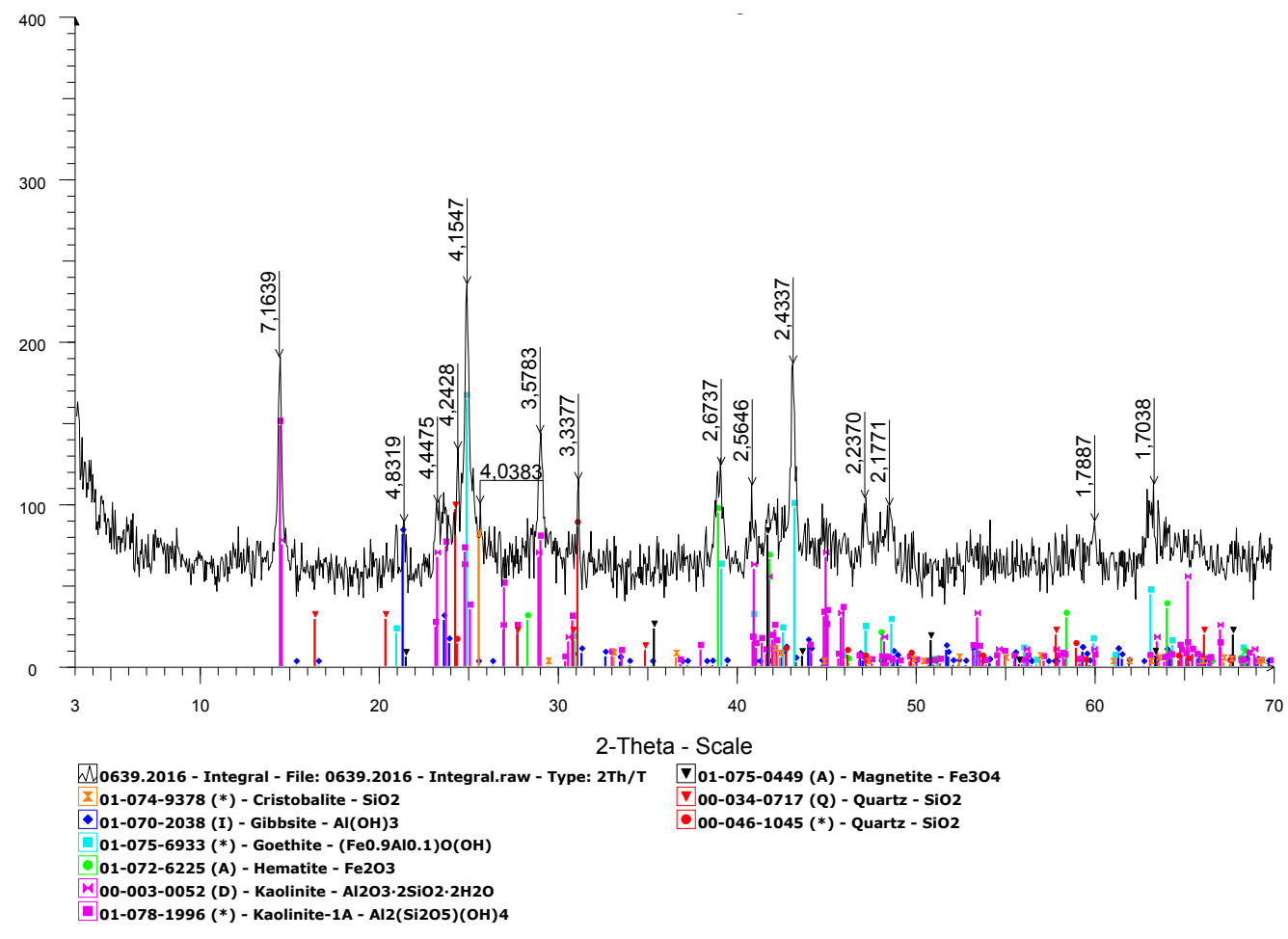

Figura 10: Difratograma do cascalho natural. 
A existência de caulinta e dos hidróxidos e óxidos hidratados de ferro e alumínio nas amostras natural e estabilizadas indicam que há presença do argilomineral do tipo 1:1, de baixa atividade, comum em solos tropicais formados pelo processo de laterização. A não existência de montimorilonita no cascalho foi confirmada, fato que impactou no pequeno ganho de resistência mecânica no processo de estabilização desse solo com a cal conforme discutido nos ensaios de compressão simples e confirmado no triaxial dinâmico.

Nos solos que predomina a magnetita ou ilmenita, observa-se a elevada massa específica desses minerais. Nas concreções lateríticas observa-se a presença de óxidos de hidratados de ferro e de alumínio que se associam à goethita, à ilmenita, à hematita e ao quartzo, conforme verificado no cascalho em estudo [3].

$\mathrm{Na}$ Tabela 14 estão apresentados os minerais principais e os subordinados presentes em cada mistura. Para a amostra utilizada na obra, devido ao acréscimo de $20 \%$ de areia, o quartzo apareceu como o mineral principal. Como minerais subordinados, foram detectados os minerais presentes no cascalho laterítico. Ainda nessa amostra, verificou-se que o acréscimo de $2 \%$ não gerou a formação de novos minerais. Para as demais misturas analisadas, verifica-se que os minerais encontrados foram os mesmos, havendo apenas algumas trocas entre os principais e os subordinados. No caso da mistura com maior teor de cal $(6 \%)$, detectou-se a presença de calcita, o que indica o aumento de resistência a partir desse teor. Esses resultados demonstram que para o cascalho em questão, os teores de cimento e cal utilizados não geram a formação de outros minerais durante as reações que ocorrem no processo de estabilização. Sendo assim, as diferenças de comportamento mecânico observadas para as diferentes misturas não estão vinculadas a nenhuma questão mineralógica.

Tabela 14: Resultados dos minerais presentes nas amostras

\begin{tabular}{l|l|l}
\hline AMOSTRAS & MINERAIS PRINCIPAIS & MINERAIS SUBORDINADOS \\
\hline $\mathrm{C}+20 \% \mathrm{~A}+2 \% \mathrm{CI}$ & Quartzo & Goethita, caulinita, hematita \\
\hline $\mathrm{C}+2 \% \mathrm{CI}$ & Caulinita e goethita & Quartzo e hematita \\
\hline $\mathrm{C}+6 \% \mathrm{CI}$ & Caulinita e goethita & Quartzo e hematita \\
\hline $\mathrm{C}+2 \% \mathrm{CA}$ & Caulinita e goethita & Quartzo e hematita \\
\hline $\mathrm{C}+6 \% \mathrm{CA}$ & Quartzo & Caulinita, goethita, gibbsita e calcita \\
\hline
\end{tabular}

Obs.: $\mathrm{C}=$ Cascalho; $\mathrm{A}=$ areia; $\mathrm{CI}=$ Cimento; $\mathrm{CA}=\mathrm{Cal}$.

Para avaliar se ocorreram ou não alterações estruturais com a estabilização química do cascalho laterítico, foram realizados ensaios de $\mathrm{MEV}$ com as seguintes amostras compactadas: cascalho, C+20\% A+2\%CI, $\mathrm{C}+2 \% \mathrm{CI}, \mathrm{C}+4 \% \mathrm{CI}, \mathrm{C}+6 \% \mathrm{CI}, \mathrm{C}+2 \% \mathrm{CA}, \mathrm{C}+4 \% \mathrm{CA}, \mathrm{C}+6 \% \mathrm{CA}$. A Figura 11 apresenta as microscopias obtidas para o aumento de $2.000 \mathrm{x}$.

A amostra de cascalho laterítico compactada apresentou microporos isolados e poucas agregações (Figura 11a). Já na amostra utilizada na obra (Figura 11b), é possível observar uma estrutura diferente da anterior, sendo que o acréscimo de areia $(20 \%)$ e cimento $(2 \%)$ causou o aparecimento de agregações isoladas e o aparecimento de mais poros.

Ao analisar a mistura do cascalho com diferentes teores de cimento, foram obtidas estruturas distintas, devido à variação do teor de cimento e, como consequência, seus comportamentos mecânicos foram alterados. Com $2 \%$ de cimento (Figura 11c), observa-se uma estrutura mais próxima da visualizada para o cascalho sem estabilização (Figura 11a), fato que explica o menor ganho de resistência para esse teor. No entanto, nota-se a existência de mais agregações e de uma estrutura em forma de filetes ou agulhas aderida em algumas partículas. Essa estrutura pode ser etringita ou outro produto resultante da hidratação do cimento. Com $4 \%$ de cimento (Figura 11d), as agregações diminuíram de tamanho, surgiram alguns microporos e a estrutura de filetes ou agulhas apareceu em maior quantidade, formando pontes entre as microagregações. Já com $6 \%$ de cimento (Figura 11e), a estrutura em forma de filetes e os microporos praticamente desapareceram, mas as agregações isoladas aumentaram, sendo que esse tipo de estrutura refletiu nos maiores valores de resistência.

SUGANYA e SIVAPULLAIAH [44] estudaram a influência do aditivo silicato de sódio (SS) misturado com cimento e um solo mole de Kuttanad. Ao adicionar $10 \%$ do aditivo à mistura, a estrutura formada apresentou uma matriz rígida e foram identificados os hidratados de silicato de cálcio (CSH) na forma de agulhas curtas e feixes finos. Esses produtos formados contribuem significativamente para a cimentação das partículas do solo e, juntamente com o aditivo, melhorou as características de resistência da mistura. KUMAR e JANEWOO [45] também notaram a formação de estruturas em forma de agulhas, compostos cimentados (CSH e CAH), que preencheram os vazios entre as partículas de um solo expansivo estabilizado e reduziram o volume dos vazios. Essas agulhas curtas observadas nos dois estudos citados são semelhantes aos filetes identificados na Figura 11c e 11d. 


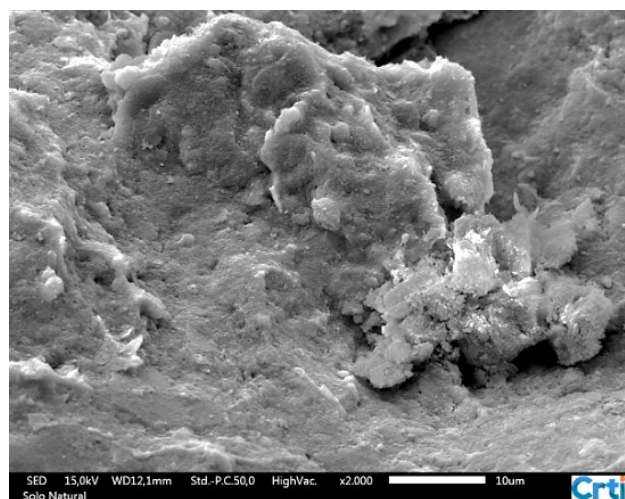

(a)

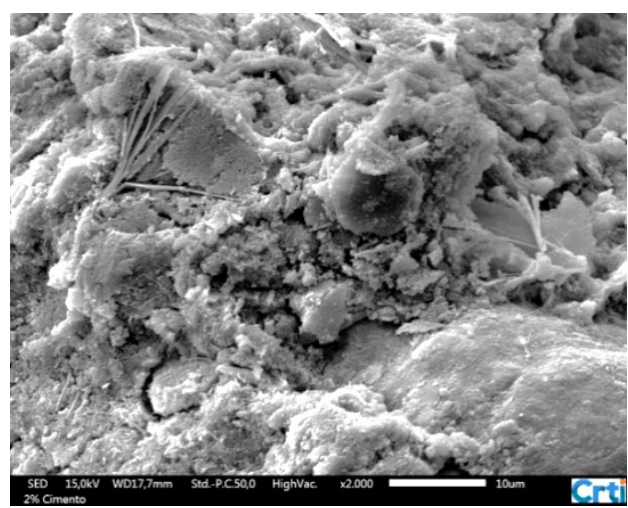

(c)

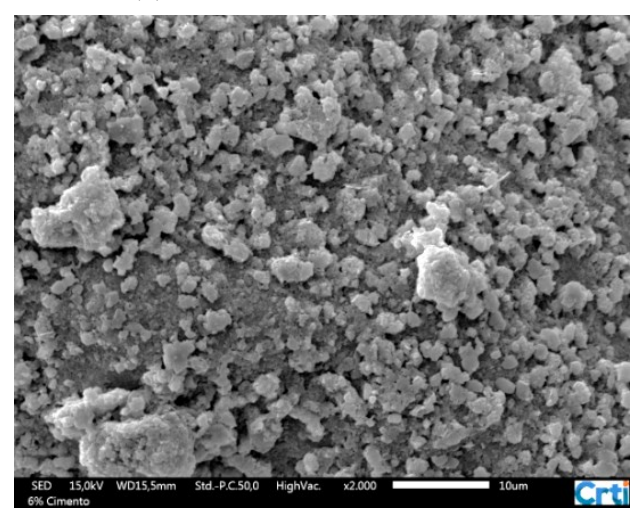

(e)

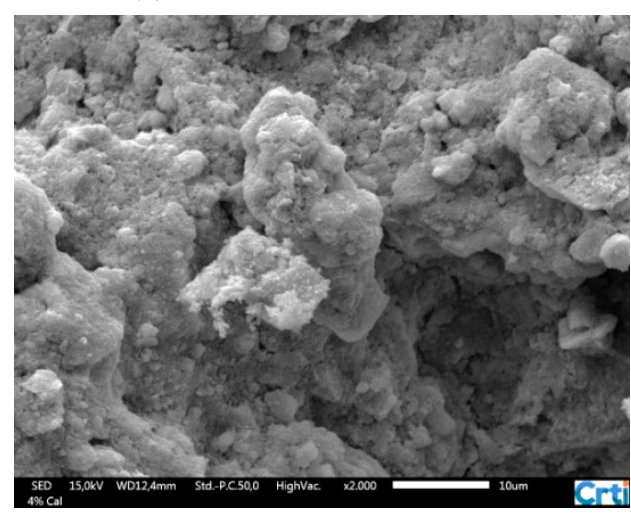

(g)

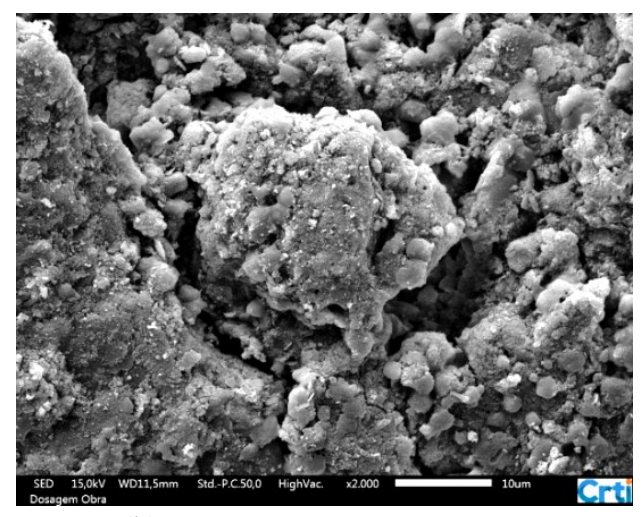

(b)

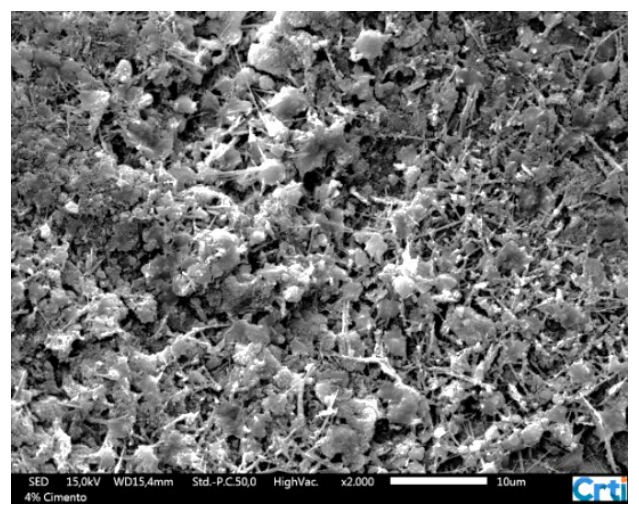

(d)

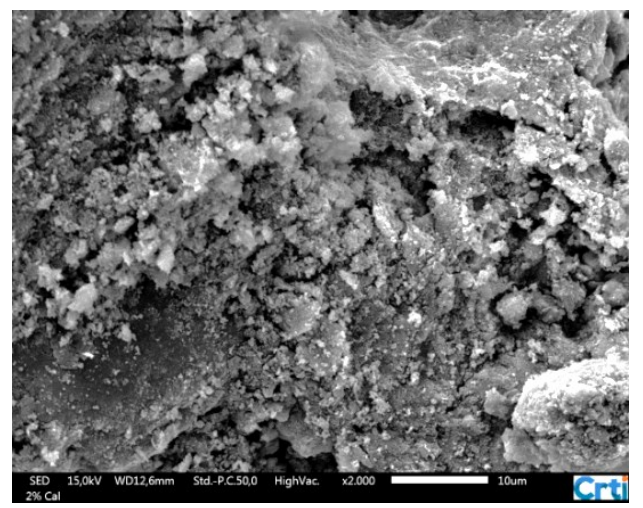

(f)

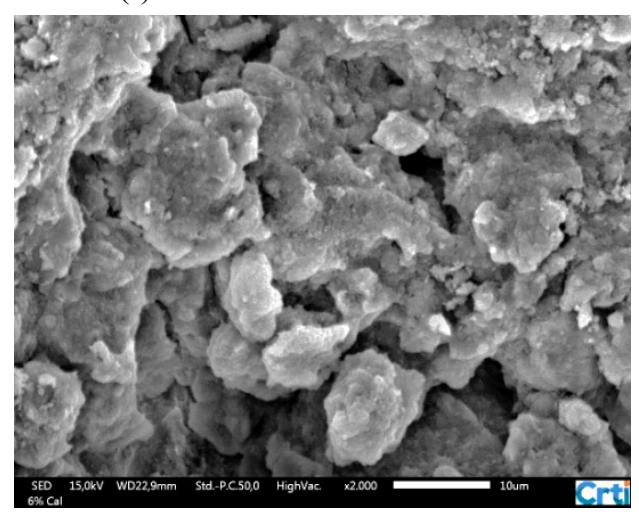

(h)

Figura 11: Imagem de MEV (x2000) das amostras (a) Cascalho natural; (b) $\mathrm{C}+20 \% \mathrm{~A}+2 \% \mathrm{CI}$; (c) $\mathrm{C}+2 \% \mathrm{CI}$; (d) $\mathrm{C}+4 \% \mathrm{CI}$; (e) $\mathrm{C}+6 \% \mathrm{CI}$; (f) $\mathrm{C}+2 \% \mathrm{CA}$; (g) $\mathrm{C}+4 \% \mathrm{CA}$; (h) $\mathrm{C}+6 \% \mathrm{CA}$.

CHANG e WOODS [46] observaram, por meio de microscopia eletrônica de varredura, a microestru- 
tura de três tipos de areias cimentadas por diferentes quantidades de agentes cimentantes. As ligações iniciais surgiram em vários pontos de contato entre as partículas de solo com cimento, indicando uma ligação fraca. Para o nível médio de cimentação, a maioria dos pontos de contatos entre as partículas manifestam por meio das ligações químicas. Já para o nível forte, a superfície das partículas de solo apresenta-se recoberta com os vazios preenchidos pelos produtos da cimentação, o que torna difícil distinguir as partículas de solo do cimento. Consequentemente, ocorreu o aumento de resistência com a redução da porosidade do material compactado. Sendo assim, para as misturas deste estudo, com $2 \%$ de cimento configura-se a situação de ligações fracas. Já as misturas com 4 e $6 \%$ de cimento, as ligações podem ser consideradas médias ou fortes. Essa análise mostra que para o solo em questão seriam indicados teores maiores que $4 \%$ de cimento para obter melhores resultados com o processo de estabilização.

HORPIBULSUK et al. [11] analisaram o efeito do tempo de cura na distribuição granulométrica das amostras compactadas na energia Proctor modificado com $10 \%$ de cimento durante o período inicial de cura (menor que 7 dias). Os autores observaram que o volume dos poros menores que $0,1 \mu \mathrm{m}$ diminuiu significativamente enquanto que o volume maior que $0,1 \mu \mathrm{m}$ aumentou ligeiramente. Durante esse período de cura, os produtos formados da cimentação preencheram os poros inferiores a $0,1 \mu \mathrm{m}$ e as partículas maiores, correspondentes à fração não hidratada, agruparam, gerando aumento dos vazios com os poros maiores. Após 7 dias de cura, o volume de poros maiores que $0,1 \mu \mathrm{m}$ tende a diminuir, enquanto que o volume dos poros menores tende a aumentar, sendo que esse fato possivelmente está relacionado com os produtos da cimentação que preenchem os poros maiores que $0,1 \mu \mathrm{m}$. Neste estudo, as amostras foram avaliadas no MEV após 31 dias de cura. Sendo assim, é observada a existência de poros menores conforme relatado no estudo de HORPIBULSUK et al. [11].

Assim, conclui-se que na mistura com $4 \%$ de cimento foram formados produtos originados da hidratação, que cristalizaram em forma de agulhas, gerando uma malha reticulada nos vazios dos poros. Nesse caso, a ação do aditivo se caracteriza pela existência de microporos preenchidos por estruturas de condensação por todo o volume que induzem um fortalecimento mecânico. Porém, para o teor de $6 \%$ cimento, a matriz formada foi mais densa, sem macroporos, apresentando melhor desempenho em termos de resistência à compressão simples e módulo de resiliência.

Ao avaliar a microestrutura das misturas do cascalho com diferentes teores de cal, observa-se que com $2 \%$ tem-se microagreações e microporos (Figura 11f). Ao adicionar 4\% (Figura 11g) e 6\% (Figura 11h) de cal, são formadas maiores agregações. Nesse caso, usar baixos teores de cal (2\%) pouco influencia na estrutura e, consequentemente, na resistência. Por outro lado, usar teores de cal acima de $4 \%$ irá alterar a estrutura e a resistência, mas o impacto no caso em questão foi pequeno.

No processo de estabilização química de solos com cal, esta reage com a sílica ou alumina presente no solo para formarem um gel, resultante das reações pozolânicas que são responsáveis pelo aumento da resistência. Já as reações correspondentes à troca de cátions, floculação e aglomeração são responsáveis pela modificação da plasticidade, contração e trabalhabilidade do solo [47, 48, 49]. No entanto, essas reações são mais impactantes para solos finos, onde esses elementos estariam livres para reagirem com a cal. Dessa forma, o uso da cal para a estabilização do cascalho laterítico avaliado nesta pesquisa não se mostrou eficiente, conforme confirmado nas análises dos valores de RCS e de MR.

As misturas de cal com solo têm como principal objetivo obter ao máximo o efeito cimentante e aproveitar os solos com melhores condições pozolânicas e relativamente com boa qualidade no estado natural, como os classificados em A-2-4, A-2-6, A-2-7, A-4 e A-6. PARODI [50] indica que as misturas devem ser realizadas com solos lateríticos que apresentam valores para o índice de plasticidade (IP) entre $15 \%$ a $20 \%$. O cascalho deste estudo foi classificado como A-2-6, mas apresentou IP de 14\%.

Verifica-se que o acréscimo de cal ao cascalho laterítico ocasionou agregação das partículas com o surgimento de aglomerados maiores do que as amostras estabilizadas com cimento. As misturas compactadas e curadas com cimento não foram uniformes e nem fisicamente contínuas; já para as misturas com cal, as estruturas mostraram ser mais semelhantes e com a tendência de formar grumos maiores com o aumento do teor de cal. Essas diferenças na microestrutura impactaram em melhores comportamentos mecânicos para a mistura de cascalho com cimento do que com cal.

\section{CONCLUSÕES}

Com os resultados apresentados neste artigo pode-se concluir que:

- $\quad$ O processo de estabilização química de solos tropicais é complexo e exige que ensaios não convencionais para área de pavimentação, como $\mathrm{MEV}$, sejam realizados para o melhor entendimento do comportamento mecânico das misturas; 
- No processo de escolha da melhor dosagem, o ensaio de ISC apresenta ser inconsistente por não considerar as características resilientes dos materiais. Inicialmente, recomenda-se a realização de ensaios de compressão simples para um estudo mais amplo com vários teores de aditivos. Em seguida, com aquelas misturas que apresentarem maior potencial de utilização, devem ser realizados ensaios triaxiais dinâmicos para a realização de análises mecanísticas e dimensionamento adequado da estrutura do pavimento;

- Durante a confecção dos corpos de prova em laboratório, devem ser adotados rigorosos controles de compactação e de condições de cura. Parâmetros como a relação água/cimento e porosidade devem ser avaliados para a seleção dos corpos de prova que serão ensaiados nos testes mecânicos, garantindo, assim, a qualidade dos resultados obtidos. Assim, constata-se que em estudos a serem desenvolvidos nessa linha torna-se interessante analisar uma amostragem maior para verificar se realmente podem existir quedas de resistência significativas. Além disso, deve-se avaliar a influência da relação água-cimento na diminuição da resistência e considerar esse parâmetro durante a moldagem dos corpos de prova;

- Para o cascalho laterítico em questão, os resultados obtidos mostram que a utilização da cal não seria recomendada. Essa solução poderia apresentar viabilidade se o cascalho apresentasse maior fração de argila ou para teores acima de $6 \%$ de cal;

- A mistura utilizada na obra, com acréscimo de areia e baixo teor de cimento, apresentou ganhos de resistência com relação ao cascalho natural. No entanto, a não utilização de areia e o acréscimo de maior quantidade de cimento (acima de 4\%) melhorou de forma considerável todos os parâmetros avaliados e, possivelmente, resultaria numa estrutura de pavimento mais durável do que a que foi executada. Porém, para a escolha da melhor mistura seria recomendado avaliar também o custo da dosagem com areia e também da mistura com acréscimo de $4 \%$ de cimento, como critério de comparação.

\section{AGRADECIMENTOS}

Os autores agradecem à Fundação CAPES pelo fornecimento da bolsa de mestrado, à Controladoria Geral do Estado de Goiás pelo apoio financeiro para a realização da pesquisa, ao Centro Tecnológico de Furnas pela realização dos ensaios de difração de raios-X e ao Centro Regional para o Desenvolvimento Tecnológico e Inovação (CRTI) pela realização dos ensaios de microscopia eletrônica de varredura.

\section{BIBLIOGRAFIA}

[1] CNT, 2015, CNT - Confederação Nacional do Transporte. Pesquisa CNT de Rodovias 2015: relatório gerencial, CNT:SEST:SENAT, 420 p. Brasília, 2015.

[2] SENÇO, W., Manual de Técnicas de Pavimentação. 1 ed, São Paulo, Pini, 1997.

[3] NOGAMI, J. S., VILliBOR, D. F. Pavimentação de Baixo Custo com Solos Lateríticos, São Paulo, Vilibor, 1995.

[4] CROFT, J. B. “The structures of soils stabilized with cementitious agents", Engineering Geology, v. 2, n. 2, pp. 63-80, Feb. 1967.

[5] CROFT, J. B. "The problem in predicting the suitability of soils for cementitious stabilization", Engineering Geology, v.2, n. 6, pp. 397-424, 1968.

[6] LITTLE, D. N., Handbook for stabilization of pavement subgrades and base courses with lime:prepared for APG Lime Company, sponsored by the National Lime Association, Kendall/Hunt Publishing Company, 1995.

[7] BELL, F. G. "Lime stabilization of clay minerals and soils", Engineering Geology, v. 42, pp. 223-237, Jan., 1996.

[8] OLA, S. A., "The potentials of lime stabilization of lateritic soils", Engineering Geology, v. 11, pp. 305317, July 6, 1977.

[9] CASANOVA, F. J. "Fundamentos (mecanismo) da dosagem físico-química do solo-cimento”, In: $26^{\mathrm{a}}$ Reunião anual de Pavimentação, Aracaju, Sergipe, Brasil, Out. 1992. 
[10] MAKUSA, G. P., Soil stabilization methods and materials in engineering practice, In: State of the art review, Department of civil, environmental and natural resources engineering, Division of mining and geotechnical engineering, Luleå University of Technology, Luleå, Suécia, 2012.

[11] HORPIBULSUK, S., RACHAN, R., CHINKULKIJNIWAT, A., et al., "Analysis of strength development in cement-stabilized silty clay from microstructural considerations", Construction and Building Materials, v. 24, pp. 2011-2021, April, 2010.

[12] JARITNGMAN, S., SOMCHAINUEK, O., TANEERANANON, P. “An investigation of lateritic soil cement for sustainable pavements”, Indian Journal of Science and Tecnology, v. 5, n. 11, pp. 3603-3606, Nov., 2012.

[13] DNER - Departamento Nacional de Estradas de Rodagem, PRO 003: Coleta de amostras deformadas de solos, Procedimento, Rio de Janeiro, 1994.

[14] GOOGLE MAPS. Coordenadas: 16²11'46"S, 49¹1'26" W. Acessado em Junho de 2016.

[15] DNER - Departamento Nacional de Estradas de Rodagem, ME 041: Solos - preparação de amostras para ensaios de caracterização, Método de Ensaio, Rio de Janeiro, 1994.

[16] ABNT - Associação Brasileira e Normas Técnicas, NBR 6457: Amostras de solo - Preparação para ensaios de compactação e ensaios de caracterização, Rio de Janeiro, 1986.

[17] DNER - Departamento Nacional de Estradas de Rodagem, ME 051: Solos - análise granulométrica Método de Ensaio, Rio de Janeiro, 1994.

[18] DNER - Departamento Nacional de Estradas de Rodagem, ME 122: Solos - determinação do limite de liquidez - Método de Ensaio, Rio de Janeiro, 1994.

[19] DNER - Departamento Nacional de Estradas de Rodagem, ME 082: Solos - determinação do limite de plasticidade - Método de Ensaio, Rio de Janeiro, 1994.

[20] ABNT - Associação Brasileira e Normas Técnicas, NBR 6508: Grãos de solos que passam na peneira de 4,8 mm - Determinação da massa específica, Rio de Janeiro, 1984.

[21] ABNT - Associação Brasileira e Normas Técnicas, NBR 6458: Grãos de pedregulho retidos na peneira de 4,8 mm determinação da massa específica, da massa específica aparente e da absorção de água, Rio de Janeiro, 1984.

[22] DNIT - Departamento Nacional de Infraestrutura e Transportes, ME 164: Solos-compactação utilizando amostras não trabalhadas-Método de Ensaio, Rio de Janeiro, 2013.

[23] ASTM - American Society for Testing and Materials, D 5102: Standard Test Method for Unconfined Compressive Strength of Compacted Soil-Lime Mixtures. West Conshohocken, PA, 1996.

[24] DNER - Departamento Nacional de Estradas de Rodagem, ME 202: Solo-cimento - Moldagem e cura de corpos de prova cilíndricos - Método de Ensaio, Rio de Janeiro, 1994.

[25] DNER - Departamento Nacional de Estradas de Rodagem, ME 049: Solos - determinação do Índice de Suporte Califórnia utilizando amostras não trabalhadas - Método de Ensaio, Rio de Janeiro, 1994.

[26] DNER - Departamento Nacional de Estradas de Rodagem, ME 201: Solo-cimento - Compressão axial de corpos de prova cilíndricos - Método de Ensaio, Rio de Janeiro, 1994.

[27] DNIT - Departamento Nacional de Infraestrutura e Transportes, ME 134: Pavimentação asfáltica - Solos - Determinação do módulo de resiliência - Método de ensaio, Rio de Janeiro, 2010.

[28] LADE, P.V., JR, D. L., YAMAMURO, J. A. "Effects of Non-Plastic Fines on Minimum and Maximum Void Ratios of Sand,', Geotechnical Testing Journal, GTJODJ, v. 21, n. 4, pp. 336-347 December 1998.

[29] PRUDENTE, J. P., REZENDE, L. R., GUIMARÃES, R. C., "Estabilização química de solos locais com cal hidratada", In: 36 Reunião anual de Pavimentação (RAPv), Curitiba, Paraná, Brasil, Agosto, 2005.

[30] DER-SP - Departamento de Estradas de Rodagem de São Paulo, ET- P00/005: Sub-base ou Base de Solo-cal - Especificação Técnica, São Paulo, 2006.

[31] NATIONAL LIME ASSOCIATION. Lime-treated Soil Construction Manual, Lime Stabilization \& Lime Modification, In: National Lime Association, Bulletin 326, 2004.

[32] DEPARTMENT OF THE ARMY. Soil stabilization for pavements mobilization construction, In: Engineering manual 1110-3-137, Corps of engineers office of the chief of engineers, 1984. 
[33] HORPIBULSUK, S., KATKAN, W., SIRILERDWATTANA, W., et al., "Strength development in cement stabilized low plasticity and coarse grained soils: laboratory and field study", Soils and Foundations, v. 46, n. 3, pp. 351-366, June, 2006.

[34] FOPPA, D., Análise de Variáveis-Chave no Controle da Resistência Mecânica de Solos Artificialmente Cimentados, Dissertação de M.Sc., Universidade Federal do Rio Grande do Sul, Porto Alegre, RS, Brasil, 2005 .

[35] JOEL, M., AGBEDE, I. O, "Mechanical-Cement Stabilization of Laterite for Use as Flexible Pavement Material", Journal of Materials in Civil Engineering, v. 23, n. 2, pp. 146-152, Feb., 2011.

[36] CONSOLI, N. C., LOPES JR, L. S., HEINECK, K. S., "Key Parameters for the Strength Control of Lime Stabilized Soils”, Journal of Materials in Civil Engineering, v. 21, n. 5, pp. 210-216, May, 2009.

[37] HUANG, YANG H. Pavement Analysis and design, 2 ed., US, Pearson-Prentice Hall, 2004.

[38] POTTURI, A. K., "Evaluation of resilient modulus of cement and cement-fiber treated reclaimed asphalt pavement (rap) aggregates using repeated load triaxial test", Tese de M.Sc., University of Texas, Arlington, TX, 2006.

[39] KHALI HANIFA, E. I., ABU-FARSAKH, M. Y., GAUTREAU G. P., Design Values of Resilient Modulus for Stabilized and Non-Stabilized Base, In: Report n. FHWA/LA.14/521, Federal Highway Administration, Baton Rouge, LA, 2015.

[40] DNER - Departamento Nacional de Estradas de Rodagem, PRO 011/79: Avaliação estrutural dos pavimentos flexíveis, Procedimento B, Rio de Janeiro, 1979.

[41] DORMON, G. M., C. T. METCALF, Design Curves for Flexible Pavements Based on Layered System Theory, In: Highway Research Record 71, Highway Research Board. Washington, D.C., 1965.

[42] DER-SP - Departamento de Estradas e Rodagem do Estado do São Paulo, IP-DE-P00/001, Projeto de pavimentação. Instrução de projeto, São Paulo, 2006.

[43] BERNUCCI, L. B., CERATTI, J. A. P., MOTTA, L. M. G., et al., Pavimentação Asfáltica: Formação Básica para Engenheiros, Rio de Janeiro, PETROBRAS-ABEDA, 2006. 3ª Reimpressão, 2010.

[44] SUGANYA, K., SIVAPULLAIAH, P. V., "Role of Sodium Silicate Additive in Cement-Treated Kuttanad Soil”, Journal of Materials in Civil Engineering, v. 28, n. 6, pp. 06016006-1-06016006-6, Jan., 2016.

[45] KUMAR, J., S., JANEWOO, U., "Stabilization of Expansive Soil with Cement Kiln Dust and RBI Grade 81 at Subgrade Level”, Geotechnical and Geological Engineering, DOI 10.1007/s10706-016-0024-8, May, 2016.

[46] CHANG, T, S., WOODS, R. D., "Effect of Particle Contact Bond on Shear Modulus, Journal of Geotechnical Engineering, v. 118, n. 8, pp. 1216-1233, August, 1992.

[47] GUIMARÃES, J. E. P., A Cal: Fundamentos e Aplicações na Engenharia Civil, 2a ed., São Paulo, Pini, 2002.

[48] LITTLE, D. N., Evaluation of structural properties of lime stabilized soils and aggregates, In: Report prepared for the National Lime Association, v. 1, 1999.

[49] OSULA, D. O. A., "Lime modification of problem laterite”, Engineering Geology, v. 30, pp. 141-154, April, 1991.

[50] PARODI, L.H. "Técnicas executivas de pavimentos estabilizados com cal atualmente utilizadas na república Argentina”, In: IV Reunião Aberta da Indústria da Cal, pp.173-210, São Paulo. 1980. 